Supporting Information for:

\title{
Effects of Covalency on Anionic Redox Chemistry in Semiquinoid-Based Metal-Organic Frameworks
}

\author{
Michael E. Ziebel ${ }^{\dagger,}$, Carlo Alberto Gaggioli ${ }^{\S}$, Ari B. Turkiewicz ${ }^{\dagger}$, Won Ryul, Laura Gagliardi ${ }^{\S}$, and \\ Jeffrey R. Long ${ }^{\dagger, *}$ \\ 'Department of Chemistry, University of California, Berkeley, California 94720, United States \\ *Materials Sciences Division, Lawrence Berkeley National Laboratory, Berkeley, California 94720 United States

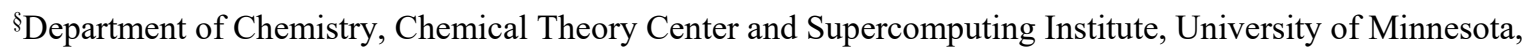 \\ Minneapolis, Minnesota 55455, United States \\ "Department of Chemical and Biomolecular Engineering, University of California, Berkeley, California 94720, \\ United States
}

\section{Table of Contents}

Additional experimental details

Figure S1. Experimental and simulated PXRD data of $1 \quad$ S-7

Table S1. Single crystal X-ray diffraction data of 2-SO $\mathbf{S O}_{4} \quad$ S-8

Figure S2. Experimental and simulated PXRD data of 2-SO $\mathbf{S O}_{4} \quad$ S-9

Figure S3. Pawley refinement of 2-SO $\mathbf{S O}_{4} \quad$ S-9

Figure S4. Experimental and simulated PXRD data of $\left(\mathrm{H}_{2} \mathrm{NMe}_{2}\right)_{1.5} \mathrm{Al}_{2}(\mathrm{dhbq})_{3} \quad \mathrm{~S}-10$

Figure S5. Magnified infrared spectra of $\mathbf{1}$ and 2-SO $\mathbf{S O}_{4} \quad$ S-10

Figure S6. Mössbauer spectra of 2-SO $\mathrm{SO}_{4} \quad \mathrm{~S}-11$

Table S2. Mössbauer fit parameters for 2-SO $\mathrm{SO}_{4} \quad \mathrm{~S}-12$

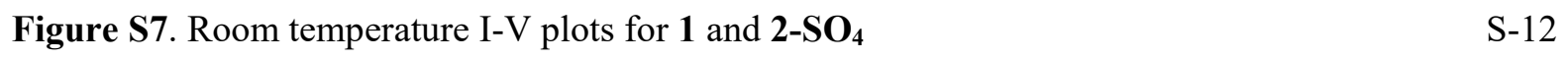

Figure S8. UV-vis-NIR diffuse reflectance spectra for $\mathbf{1}$ and 2-SO $\mathbf{S}_{4} \quad \mathrm{~S}-13$

Figure S9. Cyclic voltammograms for $\mathrm{Al}$ and $\mathrm{Zn}$ analogues of $\mathbf{1} \quad \mathrm{S}-13$

Figure S10. Mössbauer spectrum of electrochemically cycled $1 \quad$ S-14

Figure S11. Mössbauer spectrum of partially electrochemically reduced $1 \quad$ S-14

Table S3. Mössbauer fit parameters for $1 \quad$ S-15

Table S4. $U$-dependent calculated spin densities for $1 \quad$ S-15

Table S5. $U$-dependent calculated spin densities for the $\mathrm{Cr}$ analogue of $\mathbf{1} \quad \mathrm{S}-16$

Table S6. $k$-point mesh dependent calculated energies for $1 \quad$ S-16

Table S7. PBE $+U$ calculated energies for simulated reductions of $1 \quad$ S-17

Table S8. Hartree Fock exchange-dependent calculated spin densities for $1 \quad$ S-17

Table S9. HSE06 calculated energies for simulated reductions of $1 \quad$ S-18

Table S10. $\mathrm{PBE}+U$ calculated energies for simulated reductions of $\left(\mathrm{H}_{2} \mathrm{NMe}_{2}\right)_{2} \mathrm{Cr}_{2}(\mathrm{dhbq})_{3} \quad \mathrm{~S}-18$ 
Figure S12. Ligand-centered charge density distribution for reduced 1

Figure S13. Metal-centered charge density distribution for reduced 1

Figure S14. Rate-dependent discharge curves of 2-SO

$\mathrm{S}-20$

Figure S15. Rate-dependent cycling capacities of $\mathbf{1}$ and $\mathbf{2 - \mathbf { S O } _ { 4 }}$

S-20

Figure S16. Capacity and energy comparison of framework-based cathodes

S-21

Table S11. Capacity and energy comparison of framework-based cathodes

$\mathrm{S}-21$

References 


\section{Additional Experimental Details}

General Information. All manipulations of the purified materials were performed in an Ar-atmosphere MBraun glovebox. The solvents $N, N$-dimethylformamide (DMF) and tetrahydrofuran (THF) were dried using a commercial solvent purification system designed by JC Meyer Solvent Systems and were stored over $4 \AA$ molecular sieves prior to use. Carbonate solvents were dried over melted sodium metal and distilled prior to use. All other compounds were purchased and used as received. The compounds Fe(NO-

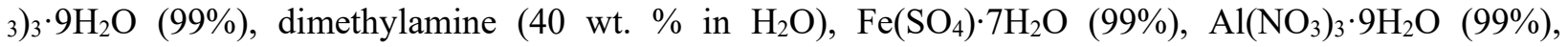
$\mathrm{Al}\left(\mathrm{NO}_{3}\right)_{3} \cdot 9 \mathrm{H}_{2} \mathrm{O}(99 \%)$, and 2,5-dihydroxybenzoquinone (98\%) were purchased from Sigma Aldrich; 2,5dichloro-3,6-dihydroxybenzoquinone (98\%), lithium tetrafluoroborate $\quad(99.99 \%)$, lithium hexafluorophosphate (99.99\%), Li(TFSI) (99.9\%), Na(TFSI) (99.9\%), and K(TFSI) (99\%) were purchased from Alfa Aesar; and sodium hydroxide (99\%) was purchased from Fisher Scientific. The compound $\left(\mathrm{H}_{2} \mathrm{NMe}_{2}\right)_{2} \mathrm{Zn}_{2}\left(\mathrm{Cl}_{2} \mathrm{dhbq}\right)_{3}{ }^{1}$ was synthesized according to a previously reported procedure. $\mathrm{C}, \mathrm{H}, \mathrm{N}$, and $\mathrm{S}$ analyses were obtained from the Microanalytical Laboratory at the University of California, Berkeley.

Synthesis of $\left(\mathbf{H}_{2} \mathbf{N M e}_{2}\right)_{1.5} \mathbf{A l}_{2}(\mathbf{d h b q})_{3}$. This compound was synthesized using a modification of the reported procedure. ${ }^{2}$ Synthesis and storage of this compound under an inert atmosphere preserves the crystallinity of the material indefinitely, while storage in air leads to loss of crystallinity (as noted in the initial report) and a color change from green to red over 24 hours. In air, a thick-walled borosilicate tube was charged with $140 \mu \mathrm{L}$ of a freshly prepared aqueous $1 \mathrm{M} \mathrm{Al}\left(\mathrm{NO}_{3}\right)_{3}$ solution, DMF $(1.4 \mathrm{~mL})$, 2,5dihydroxybenzoquinone ( $40 \mathrm{mg}, 0.19 \mathrm{mmol}$ ), and sodium hydroxide (40 $\mu \mathrm{L}$ of a $0.2 \mathrm{M}$ aqueous solution). The reaction mixture was degassed with three freeze-pump-thaw cycles, after which the tube was flame sealed and heated to $120^{\circ} \mathrm{C}$ for 16 hours. The reaction mixture was then cooled, transferred into a Vacuum Atmospheres glovebox with a humid atmosphere, and filtered. The resulting microcrystalline green powder was soaked in fresh DMF for $16 \mathrm{~h}$, and was then recollected by filtration. This washing procedure was repeated two more times until the filtrate was colorless. The remaining microcrystalline solid was rinsed with $1 \mathrm{~mL}$ of THF and then dried under reduced pressure for $20 \mathrm{~min}$ to afford the solvated product. Yield: $25 \mathrm{mg}(67 \%)$. The solvated material was used directly for electrochemical characterization. We note that small amounts of an unidentified phase impurity are observed in synchrotron diffraction data, but could not be observed on a laboratory diffractometer.

Mössbauer Spectroscopy. Iron-57 Mössbauer spectra were obtained at $100 \mathrm{~K}$ with a constant acceleration spectrometer and a cobalt-57 rhodium source. Prior to measurements, the spectrometer was calibrated at $290 \mathrm{~K}$ with $\alpha$-iron foil. The reported isomer shifts are relative to the $\alpha$-iron foil. Samples were prepared and sealed inside an Ar atmosphere glovebox and contained roughly $2 \mathrm{mg} / \mathrm{cm}^{2}$ of iron. The as-synthesized frameworks were diluted with boron nitride, while ex situ electrochemical samples were measured as 
composite electrodes with a carbon-cloth backing. All spectra were fit with symmetric Lorentzian quadrupole doublets using the WMOSS Mössbauer Spectral Analysis Software. ${ }^{3}$

UV-Visible-NIR Spectroscopy. UV-vis-NIR diffuse reflectance spectra were collected with a CARY 5000 spectrophotometer interfaced with Varian WinUV software. Spectra were collected in a Praying Mantis airfree diffuse reflectance cell with barium sulfate powder as the non-absorbing matrix. The Kubelka-Munk conversion $[F(R)$ vs. wavenumber] of the raw diffuse reflectance spectrum ( $R$ vs. wavenumber) was obtained by applying the formula $F(R)=(1-R)^{2} / 2 R$. The resulting spectra were then normalized with the maximum $F(R)$ for each spectrum set equal to 1 . For measurement of the reduced sample of 1 , an electrode was prepared for electrochemical reduction with a 90:10 weight percent mixture of 1 and PVDF. Conductive carbon was not used to avoid its contribution to the absorbance spectrum. The sample was reduced at $10 \mathrm{~mA} / \mathrm{g}$ to $1.8 \mathrm{~V}$, then held at that potential for $8 \mathrm{~h}$. The carbon cloth electrode was removed from the cell, suspended in THF, and sonicated to obtain the reduced sample as a powder. Due to the

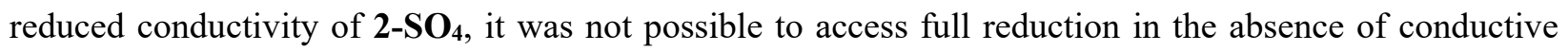
carbon, complicating interpretation of UV-vis-NIR data.

Infrared Spectroscopy. Infrared spectra were collected on a Perkin Elmer Avatar Spectrum 400 FTIR spectrometer equipped with a Pike attenuated total reflectance accessory. A homebuilt glovebag attachment was used to perform air-free measurements under a dinitrogen atmosphere. We note that infrared spectra for as-synthesized $\mathbf{1}$ and $\mathbf{2 - \mathbf { S O } _ { 4 }}$ were collected prior to THF exchange and activation to maintain a similar pore environment to the reduced samples (which are solvated with propylene carbonate). The same reduced sample used for UV-vis-NIR spectroscopy was used for collecting the infrared spectrum. For 2-SO4, it was necessary to include conductive carbon into the electrode mixture to obtain a fully reduced sample.

Powder X-Ray Diffraction. Microcrystalline powder samples of 1, 2-SO, and $\left(\mathrm{H}_{2} \mathrm{NMe}_{2}\right)_{1.5} \mathrm{Al}_{2}(\mathrm{dhbq})_{3}$ were loaded into $1.0 \mathrm{~mm}$ boron-rich glass capillaries inside an argon atmosphere glovebox, and the capillaries were flame sealed. Powder X-ray diffraction data were subsequently collected at beamline 17BM at the Advanced Photon Source at Argonne National Laboratory. Diffraction patterns were collected at room temperature with wavelengths of $0.45118 \AA$ (1) or $0.45236 \AA\left(\mathbf{2}-\mathbf{S O}_{4},\left(\mathrm{H}_{2} \mathrm{NMe}_{2}\right)_{1.5} \mathrm{Al}_{2}(\mathrm{dhbq})_{3}\right)$. For $\left(\mathrm{H}_{2} \mathrm{NMe}_{2}\right)_{2} \mathrm{Zn}_{2}\left(\mathrm{Cl}_{2} \mathrm{dhbq}\right)_{3}$ a small amount of DMF-soaked, microcrystalline powder was placed onto the zero-background plate of a Bruker D8 Advance Diffractometer. Powder X-ray diffraction data were subsequently collected using a Cu-Ka $(\lambda=1.5406 \AA)$ X-ray source between $2^{\circ}<2 \theta<40^{\circ}$ at a scan rate of 0.2 seconds per step with a step size of $0.02^{\circ}$. We note that dried samples of $\left(\mathrm{H}_{2} \mathrm{NMe}_{2}\right)_{2} \mathrm{Zn}_{2}\left(\mathrm{Cl}_{2} \mathrm{dhbq}\right)_{3}$ showed evidence of breathing behavior and changes in the $c$-axis lattice parameter.

For ex situ powder X-ray diffraction measurements, a sample of 1 was electrochemically reduced on a carbon cloth support. Samples were reduced at $10 \mathrm{~mA} / \mathrm{g}$ to $1.8 \mathrm{~V} \mathrm{vs.} \mathrm{Li}^{0 /+}$, and were then reduced at that 
potential for 6 hours. The carbon cloth electrodes were then removed from the electrochemical cell, and sonicated in THF to obtain the reduced sample as a free powder. Samples were then loaded into boron-rich glass capillaries and sealed. Powder X-ray diffraction data were collected at beamline 12.2 .2 at the Advanced Light Source at Lawrence-Berkeley National Laboratory. Diffraction patterns were collected at room temperature with a wavelength of $0.4980 \AA$.

For 2-SO $\mathbf{S}_{4}$, a standard peak search, followed by indexing via single-value decomposition, as implemented in TOPAS-Academic v4.1, enabled determination of approximate unit-cell dimensions. ${ }^{4}$ Using TOPAS-Academic, precise unit-cell dimensions were determined by performing a structureless Pawley refinement.

Single Crystal X-ray Diffraction. X-ray diffraction analysis was performed on single crystals coated with Paratone-N oil and mounted on a MiTeGen loops. The crystals were frozen at $100 \mathrm{~K}$ by an Oxford Cryosystems Cryostream 700 Plus. Data were collected at Beamline 12.2.1 at the Advanced Light Source at Lawrence Berkeley National Laboratory using synchrotron radiation $(\lambda=0.7288 \AA$ ) on a Bruker D8 diffractometer equipped with a Bruker PHOTON II CPAD detector. Raw data were integrated and corrected for Lorentz and polarization effects using Bruker AXS SAINT software. ${ }^{5}$ Absorption corrections were applied using SADABS. ${ }^{6}$ The structures were solved using intrinsic phasing with $\mathrm{SHELXT}^{7}$ and refined using SHELXL ${ }^{8}$ operated in the OLEX $2^{9}$ interface. No significant crystal decay was observed during data collection. Thermal parameters were refined anisotropically for all non-hydrogen atoms. Poor data quality required truncating the data at a resolution of $1.2 \AA$. Significant electron density remained in the voids of the structures resulting from disordered framework cations and solvent molecules that could not be modeled. Consequently, the unassigned electron density was accounted for using SQUEEZE ${ }^{10}$ as implemented in the PLATON $^{11}$ interface.

Electrochemical Characterization. For galvanostatic measurements, working electrodes were prepared from a composite of activated metal-organic framework (80 wt \%), Super P conductive carbon (10 wt \%), and PVDF (10 wt \%) suspended in THF (1-2 mL). For cyclic voltammetry measurements, composite mixtures with a 60/30/10 wt \% (framework / Super P / PVDF) ratio were used. The suspensions were dispersed with a horn sonicator (15 min), and dropcast onto carbon cloth (Fuel Cell Earth) at $120{ }^{\circ} \mathrm{C}$. The electrodes were compressed with a hand press, then dried at $120^{\circ} \mathrm{C}$ for one hour to remove residual solvent molecules in the pores. The carbon cloth electrodes were then transferred to a Swagelok union $\mathrm{T}$ cell with titanium current collectors $\left(1.26 \mathrm{~cm}^{2}\right)$, alkali metal reference and counter electrodes, and electrolyte-soaked quartz cloth as the separator. Electrodes typically contained 5 to $15 \mathrm{mg}$ of active material. The larger samples masses were required for ex situ spectroscopy and diffraction experiments.

Electrochemical data were collected using a Bio-Logic VMP-3 Multipotentiostat/Galvanostat. Following cell assembly, cells were allowed to relax at open circuit for at least 12 hours. Galvanostatic 
measurements were performed with potential and capacity limitations, while cyclic voltammetry measurements were collected at 30 or $50 \mu \mathrm{V} / \mathrm{s}$. Data were analyzed with the free software package EC Lab v10.37 offered by Bio-Logic.

Electronic Conductivity Measurements. Conductivity measurements were conducted in a home-built two electrode screw cell reported previously ${ }^{12}$ with contact areas of $\sim 0.05 \mathrm{~cm}^{2}$. Pellets of $\mathbf{1}$ or 2-SO $\mathbf{S}_{4}$ were pressed between two copper rods of known diameter with contacts polished to a mirror finish. Sample thicknesses were measured with a caliper and were typically on the order of $100 \mu \mathrm{m}$. Room temperature conductivity measurements were obtained using a Bio-Logic VMP-3 multipotentiostat fitted to an argon glovebox.

Additional Computational Details. Electronic structure calculations were performed using the PBE+U approach. U values (applied on the metal ions) were chosen such that the spin density on the metal most closely matched that observed in experiment, i.e. $\mathrm{S}=5 / 2$ for high spin $\mathrm{Fe}(\mathrm{III})$ in $\mathbf{1}$ and $\mathrm{S}=3 / 2$ for $\mathrm{Cr}$ (III) in the $\mathrm{Cr}$ phase. Screening different values for $U$ provided optimal energies of $\mathrm{U}=9 \mathrm{eV}$ for $\mathbf{1}$ and $\mathrm{U}=4 \mathrm{eV}$ for the $\mathrm{Cr}$ phase (Tables S4-S5). For 1, a value of $\mathrm{U}=9 \mathrm{eV}$ yields a spin density on the iron ion of 4.7, close to the expected value of 5 . Higher values yielded an abrupt change in the magnetization of the system, producing a non-physical structure. We note that the atomic spin density generated by VASP is integrated in spheres of fixed radii, so the spin density values listed in Table S4 may not be fully quantitative. For the Cr phase, a value of $U=4 \mathrm{eV}$ generated a spin density of 3, matching the expected value.

Single point calculations were performed on the dianionic unit cell (the as-synthesized framework) for 1 (optimized with a $1 \times 1 \times 2 k$-point mesh and $\mathrm{U}=9 \mathrm{eV}$ ) by increasing the $k$-point mesh and monitoring changes to the total energy (Table S6). The total energy using a 1x1 x $k$-point mesh differs by only $3 \mathrm{meV}$ per atom with respect to higher $k$-point meshes, suggesting the $1 \times 1 \times 2 k$-point mesh is sufficient for these systems.

For calculations using the HSE06 functional with a modified percentage of Hartree-Fock (HF) exchange, the geometries were optimized with $\mathrm{PBE}+\mathrm{U}$, and single point HSE06 calculations were performed at the $\Gamma$ point, with other computational details matching those of the $\mathrm{PBE}+\mathrm{U}$ calculations. Different levels of HF exchange were tested from $20 \%$ to $100 \%$, revealing that $100 \%$ HF exchange most closely matches the experimental spin density for the iron ions (Table S8).

Discussion of Oxidation Assignment for 2-SO $\mathbf{S O}_{4}$. As discussed in the text, oxidation states of $\mathrm{Fe}$ ions were determined via Mössbauer spectroscopy. Using the assumption that each $\mathrm{Fe}^{\mathrm{III}}$ ion transfers one electron to the ligand scaffold, the extent of ligand reduction in $\mathbf{2}-\mathbf{S O}_{4}$ was obtained. This yielded a framework formula $\left[\mathrm{Fe}^{\mathrm{II}} \mathrm{Fe}^{\mathrm{III}}{ }_{2}\left(\mathrm{Cl}_{2} \mathrm{dhbq}\right)^{2-}\left(\mathrm{Cl}_{2} \mathrm{dhbq}^{3-}\right)_{2}\left(\mathrm{SO}_{4}\right)_{2}\right]^{4-}$. The number of charge-balancing dimethylammonium cations within the pores was then determined from the charge of the parent framework. 


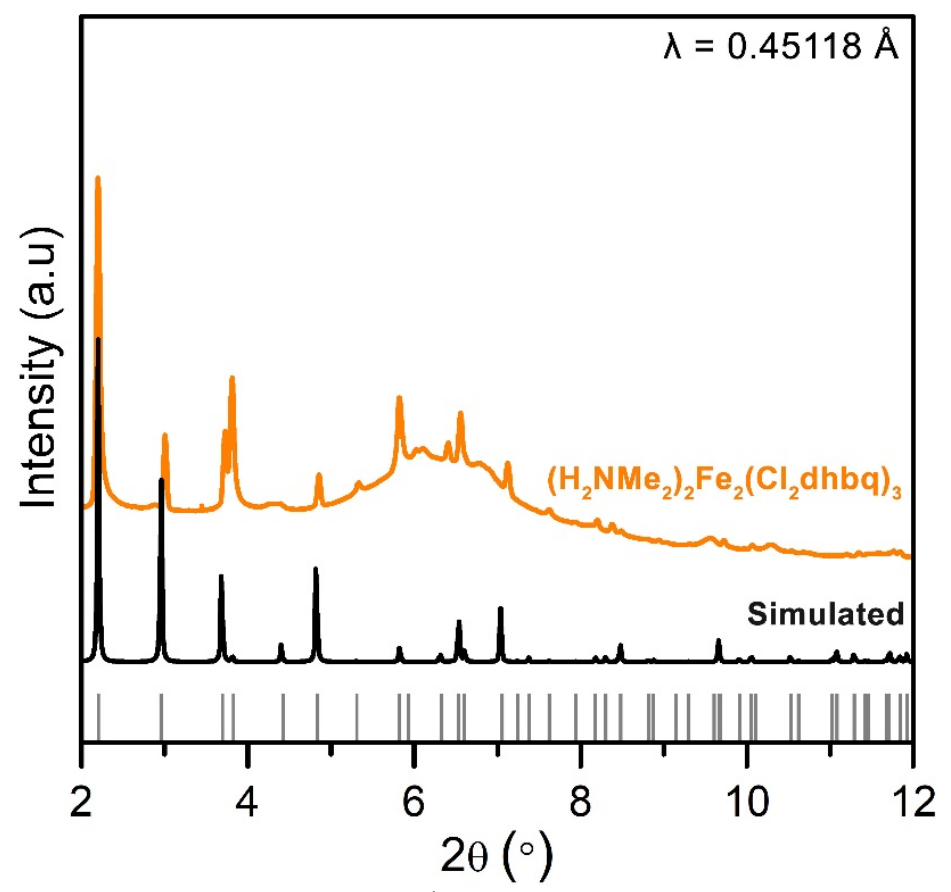

Figure S1. Experimental (orange) and simulated ${ }^{1}$ (black) powder X-ray diffraction data for 1 with tick marks indicating allowed reflections. Preferred orientation effects and partial $c$-axis disorder explain the variation in peak intensities between experimental and simulated data, while slight variation in the $c$-axis lattice spacing explains the slight shift of some reflections. The broad amorphous feature from 5 to $8^{\circ}$ is due to the borosilicate capillary used during the measurement. 
Table S1. Single crystal X-ray diffraction data and structure refinement for $\left(\mathrm{H}_{2} \mathrm{NMe}_{2}\right)_{4} \mathrm{Fe}_{3}\left(\mathrm{Cl}_{2} \mathrm{dhbq}\right)_{3}\left(\mathrm{SO}_{4}\right)_{2}$ (2-SO $\left.{ }_{4}\right)$.

\begin{tabular}{|c|c|}
\hline & $\left(\mathrm{H}_{2} \mathrm{NMe}_{2}\right)_{4} \mathrm{Fe}_{3}\left(\mathrm{Cl}_{2} \mathrm{dhbq}\right)_{3}\left(\mathrm{SO}_{4}\right)_{2} \bullet 1.25(\mathrm{DMF})$ \\
\hline Formula & $\mathrm{C}_{31.5} \mathrm{H}_{31.5} \mathrm{Cl}_{6} \mathrm{Fe}_{3} \mathrm{~N}_{4.5} \mathrm{O}_{24.5} \mathrm{~S}_{2}$ \\
\hline Temperature $(\mathrm{K})$ & $100(2)$ \\
\hline Crystal System & Hexagonal \\
\hline Space Group & $P 6_{3} / \mathrm{mcm}$ \\
\hline$a, b, c(\AA)$ & $\begin{array}{l}18.1779(8), \\
18.1779(8), \\
17.9824(9)\end{array}$ \\
\hline$\alpha, \beta, \gamma\left(^{\circ}\right)$ & $90,90,120$ \\
\hline$V\left(\AA^{3}\right)$ & $5145.9(5)$ \\
\hline $\mathrm{Z}$ & 4 \\
\hline $\begin{array}{l}\text { Radiation, } \\
\lambda(\AA)\end{array}$ & $\begin{array}{c}\text { Synchrotron, } \\
0.7288\end{array}$ \\
\hline $\begin{array}{c}2 \Theta \text { Range for Data } \\
\text { Collection }\left(^{\circ}\right)\end{array}$ & 2.652 to 35.352 \\
\hline Completeness to $2 \Theta$ & $\begin{array}{c}99.8 \% \\
\left(2 \Theta=35.352^{\circ}\right)\end{array}$ \\
\hline $\begin{array}{l}\text { Data / Restraints / } \\
\text { Parameters }\end{array}$ & $599 / 33 / 81$ \\
\hline Goodness of Fit on $F^{2}$ & 1.166 \\
\hline $\begin{array}{l}R_{1}^{a}, w R_{2}^{b} \\
(I>2 \sigma(I))\end{array}$ & $\begin{array}{l}0.0470 \\
0.1238\end{array}$ \\
\hline $\begin{array}{l}R_{1}^{a}, w R 2^{b} \\
\text { (all data) }\end{array}$ & $\begin{array}{c}0.0502 \\
0.1268\end{array}$ \\
\hline $\begin{array}{l}\text { Largest Diff. } \\
\text { Peak and Hole } \\
\quad\left(\mathrm{e} \AA^{-3}\right)\end{array}$ & $\begin{array}{c}0.200 \text { and } \\
-0.277\end{array}$ \\
\hline
\end{tabular}




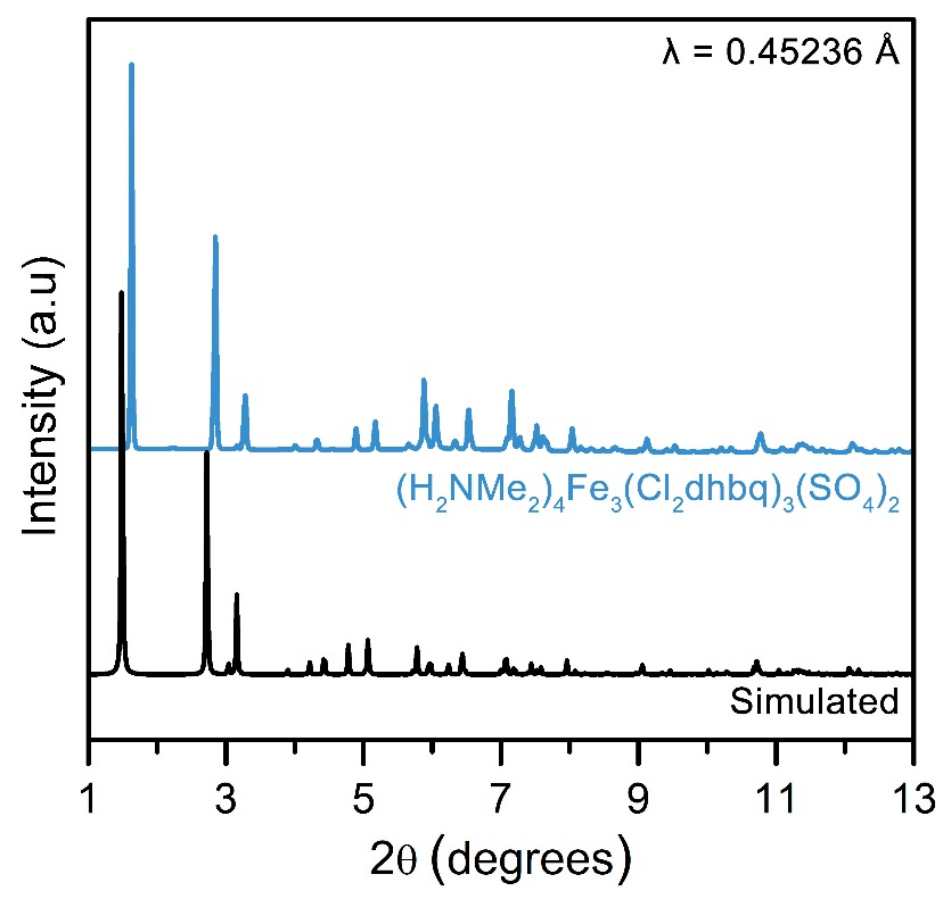

Figure S2. Experimental (blue) and simulated (black) powder X-ray diffraction data for 2-SO4. Preferred orientation effects explain the variation in peak intensities between experimental and simulated data, while the temperature difference of data collection for single crystal $(100 \mathrm{~K})$ and powder (room temperature) diffraction experiments explains the difference in peak positions.

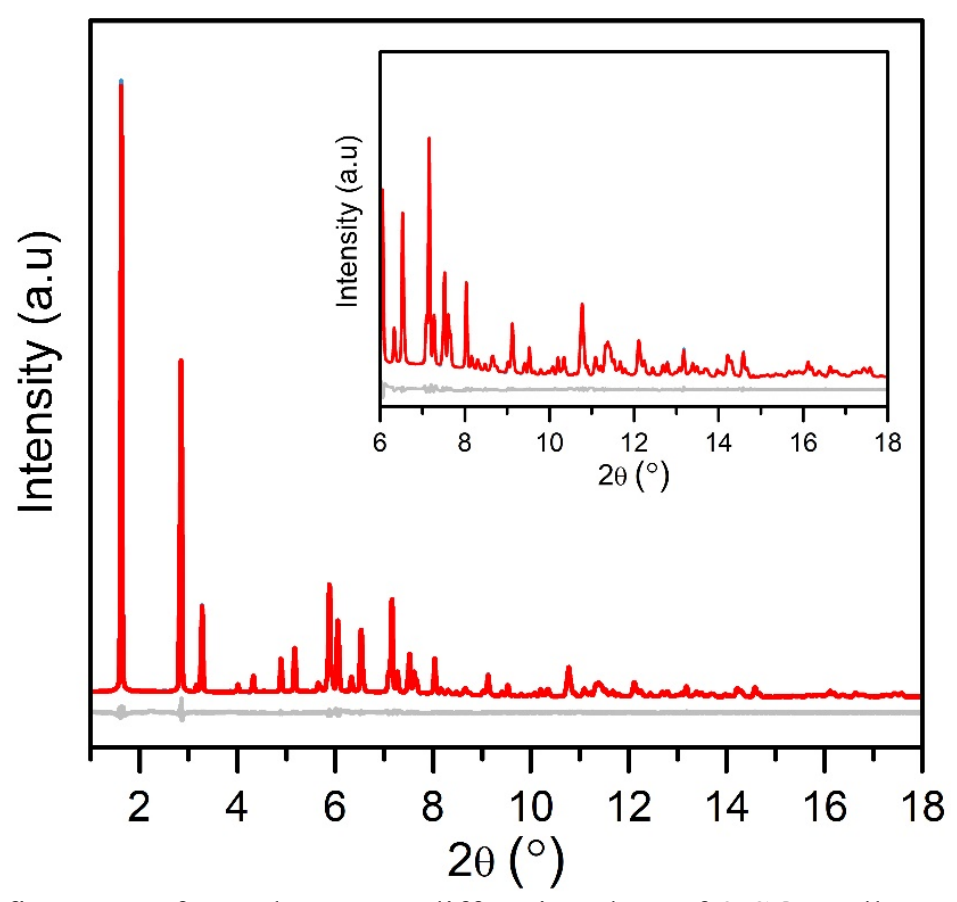

Figure S3. Pawley refinement of powder X-ray diffraction data of 2-SO 4 collected at room temperature with $\lambda=0.45236 \AA$. Light blue and red lines represent the observed and calculated diffraction patterns, respectively. The gray line represents the difference between the observed and calculated powder patterns. The observed space group is $P 6_{3} / \mathrm{mcm}$. Calculated unit cell parameters are $a=18.3453(2) \AA, c=18.1629(2)$ $\AA, V=5302.5(1) \AA^{3}$. $\mathrm{R}_{\mathrm{wp}}=3.46 \%, \mathrm{R}_{\mathrm{p}}=2.26 \%$. The slightly larger unit cell parameters compared to the single crystal data are due to the higher temperature of the powder X-ray diffraction data. 


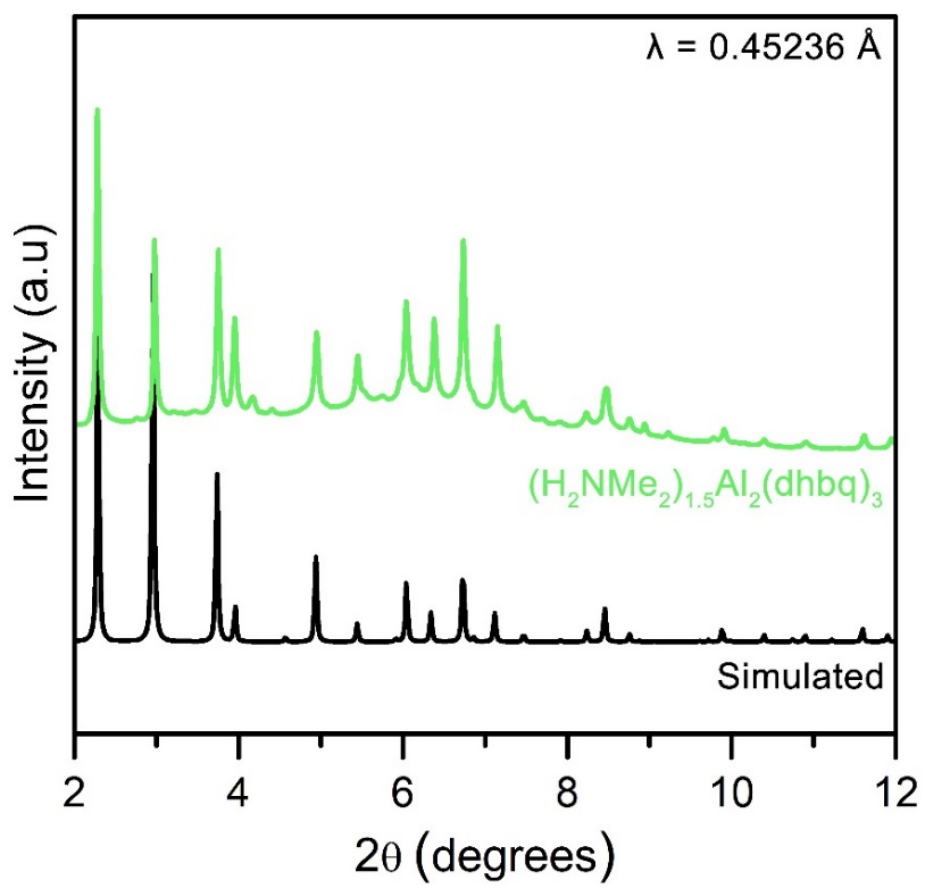

Figure S4. Experimental (light green) and simulated $^{2}$ (black) powder X-ray diffraction data for the aluminum analogue of $\mathbf{1},\left(\mathrm{H}_{2} \mathrm{NMe}_{2}\right)_{1.5} \mathrm{Al}_{2}(\mathrm{dhbq})_{3}$. Slight phase impurities are observed, but these are not expected to contribute to the electrochemical data presented herein. The broad amorphous feature from 5 to $8^{\circ}$ is due to the borosilicate capillary used during the measurement.

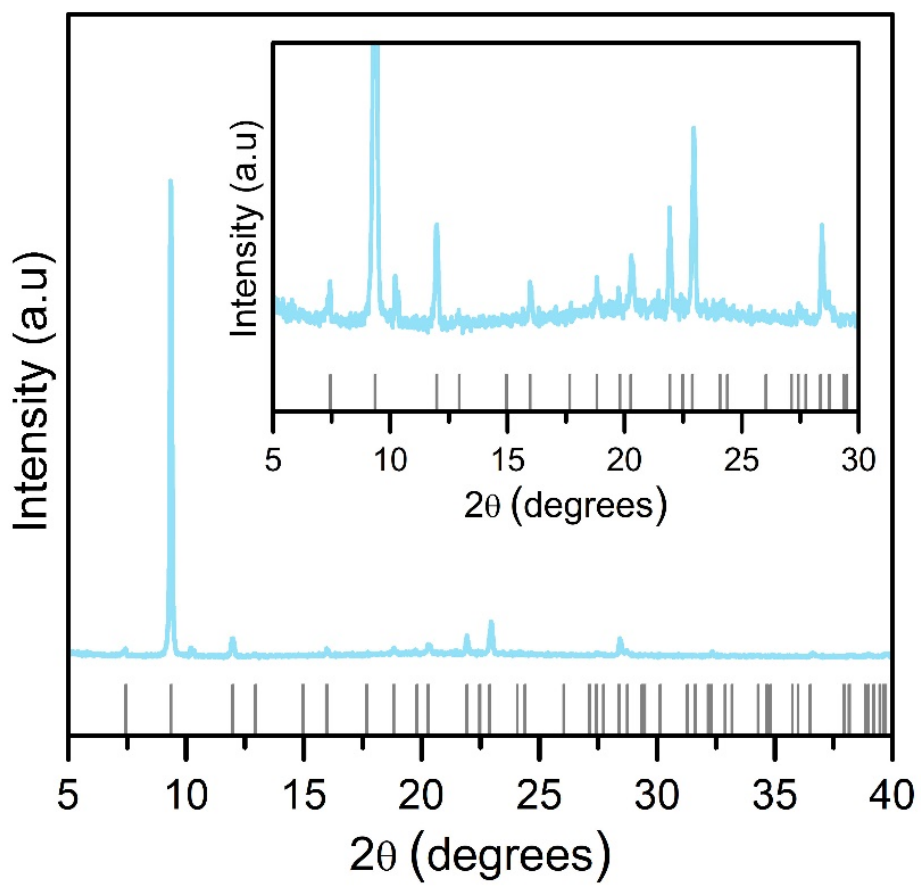

Figure S5. Powder X-ray diffraction data for DMF-soaked $\left(\mathrm{H}_{2} \mathrm{NMe}_{2}\right)_{2} \mathrm{Zn}_{2}\left(\mathrm{Cl}_{2} \mathrm{dhbq}\right)_{3}$ collected at $\lambda=1.5406$ $\AA$ with tick marks corresponding to the allowed reflections for the space group $P-31 \mathrm{~m}$ with unit cell parameters $a=13.69 \AA$ and $c=9.44 \AA$. Inset shows magnified pattern from 5 to $30^{\circ}$. The enhanced intensity of the $(0,0,1)$ reflection $\left(\sim 9.4^{\circ}\right)$ is due to preferred orientation of the plate-like crystals. The small peak near $11^{\circ}$ is due to partial drying of the sample over the course of the measurement. 

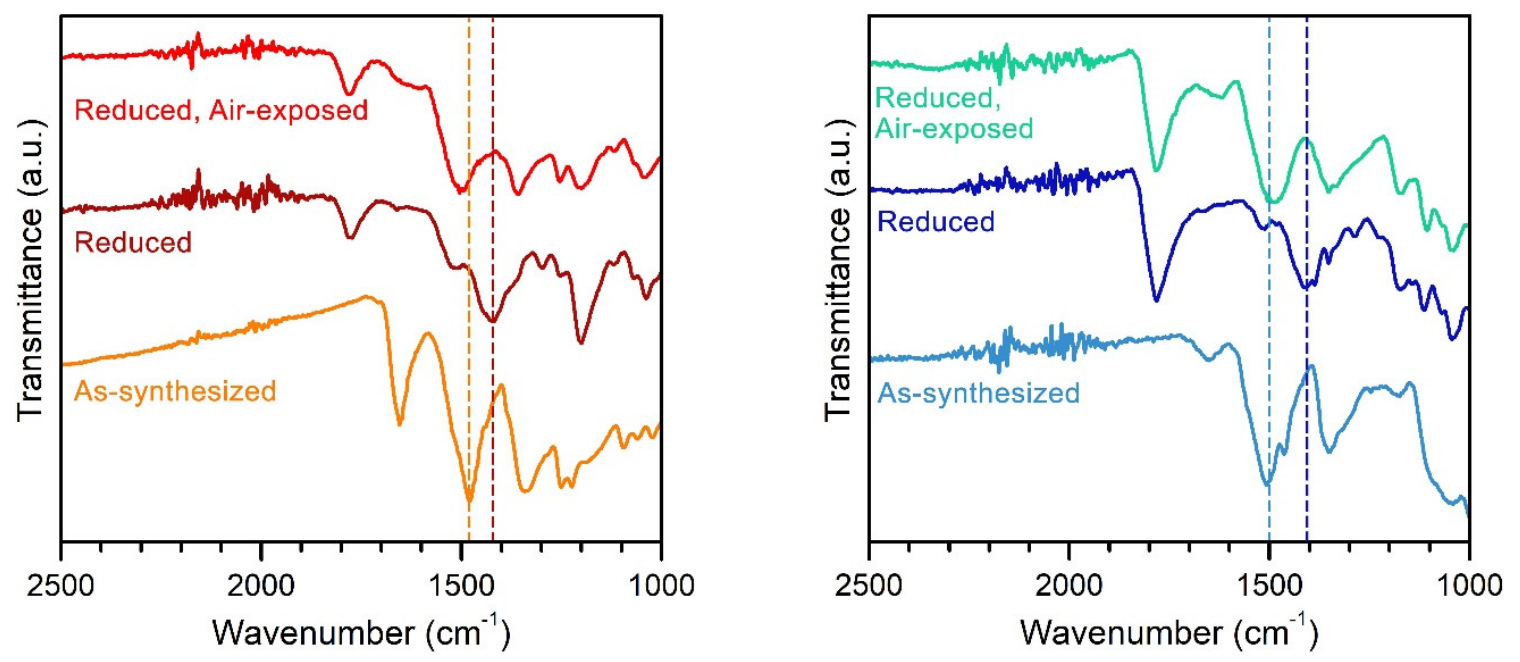

Figure S6. Magnified view of the infrared spectra of $\mathbf{1}$ (left) and 2-SO 4 (right) as-synthesized and at full reduction. The dashed lines highlight the shift in the quinone stretching frequency upon electrochemical reduction. Features at 1650 and $1790 \mathrm{~cm}^{-1}$ correspond to DMF and propylene carbonate respectively.

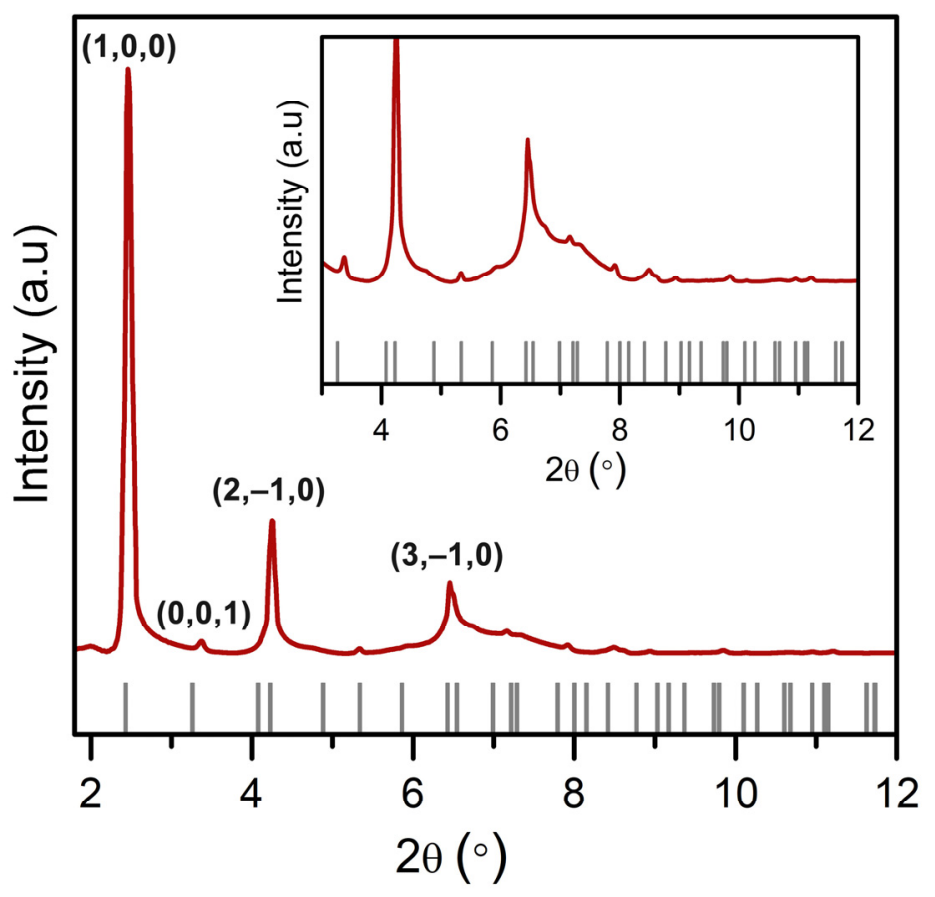

Figure S7. Powder X-ray diffraction data for reduced $1\left(x=4\right.$ in $\left.\mathrm{Li}_{x}\left(\mathrm{H}_{2} \mathrm{NMe}_{2}\right)_{2} \mathrm{Fe}_{2}\left(\mathrm{Cl}_{2} \mathrm{dhbq}\right)_{3}\right)$ collected at $0.4980 \AA$. Tick marks correspond to the expected reflections for as-synthesized $\mathbf{1}$. Numbers in parentheses correspond to the $(h, k, l)$ values for certain reflections. Reduced intensity for peaks containing a $c$-axis component may suggest partial exfoliation upon reduction, but strong reflections in $a b$-plane suggest retention of honeycomb structure upon reduction. Slight deviations in peak positions relative to the tick marks are due to changes in the unit cell dimensions upon reduction. 


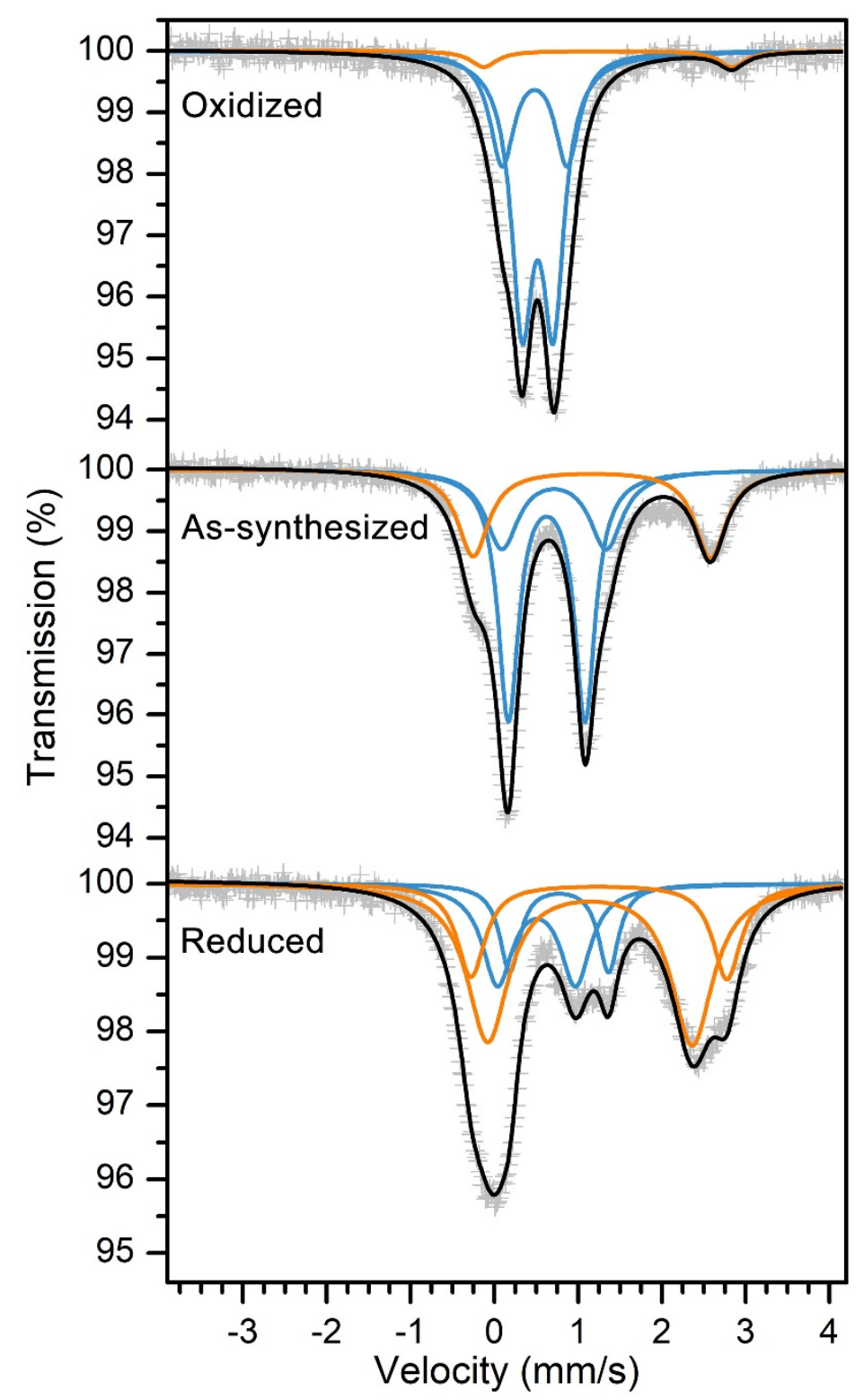

Figure S8. Mössbauer spectra for 2-SO reduction. Black, blue and orange lines corresponds to the overall fit, fits to high spin $\mathrm{Fe}^{\mathrm{III}}$ sites, and fits to high spin $\mathrm{Fe}^{\mathrm{II}}$ sites, respectively. Full fit parameters are listed in Table S2. 
Table S2. Parameters for fits of the Mössbauer spectra of $\mathbf{2}-\mathbf{S O}_{4}$ at full oxidation, as synthesized, and at full reduction. Fits corresponding to high spin $\mathrm{Fe}^{\mathrm{II}}$ sites are shown in orange, and fits corresponding to high spin $\mathrm{Fe}^{\mathrm{III}}$ sites are shown in blue.

\begin{tabular}{lcccc}
\hline Compound & $\begin{array}{c}\delta \\
(\mathrm{mm} / \mathrm{s})\end{array}$ & $\begin{array}{c}\Delta E_{Q} \\
(\mathrm{~mm} / \mathrm{s})\end{array}$ & $\begin{array}{c}\Gamma \\
(\mathrm{mm} / \mathrm{s})\end{array}$ & $\begin{array}{c}\text { Fractional } \\
\text { Area }\end{array}$ \\
\hline 2-SO $_{4}$, & $0.487(13)$ & $0.78(5)$ & $0.35(6)$ & $0.31(10)$ \\
Oxidized & $0.519(6)$ & $0.37(2)$ & $0.31(2)$ & $0.64(10)$ \\
& $1.369(50)$ & $2.99(11)$ & $0.35(18)$ & $0.05(1)$ \\
& & & & \\
$\mathbf{2 - S O}_{4}$ & $0.625(6)$ & $0.91(1)$ & $0.30(1)$ & $0.51(6)$ \\
& $0.714(19)$ & $1.25(7)$ & $0.46(6)$ & $0.26(1)$ \\
& $1.159(11)$ & $2.80(2)$ & $0.44(5)$ & $0.23(6)$ \\
$\mathbf{2 - S O}_{4}$, & $0.508(23)$ & $0.92(5)$ & $0.43(6)$ & $0.22(3)$ \\
Reduced & $0.777(14)$ & $1.18(2)$ & $0.29(6)$ & $0.14(3)$ \\
& $1.143(19)$ & $2.43(4)$ & $0.56(4)$ & $0.45(5)$ \\
& $1.246(12)$ & $3.05(3)$ & $0.39(6)$ & $0.20(5)$ \\
\hline
\end{tabular}
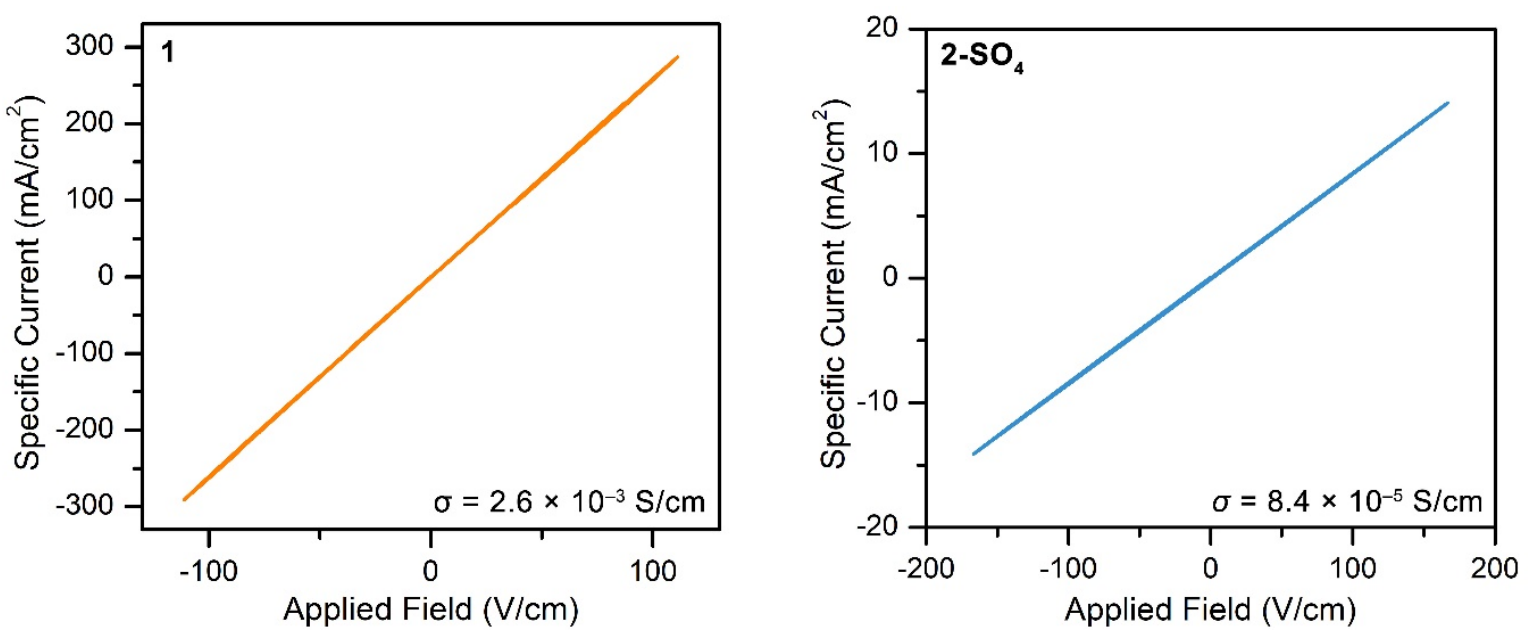

Figure S9. Room temperature current-voltage plots for $\mathbf{1}$ (left) and 2-SO 4 (right) collected as two-point measurements on pressed pellets. Measurements were performed on activated samples. The pellet of $\mathbf{1}$ had a thickness of $90 \mu \mathrm{m}$ and an area of $0.052 \mathrm{~cm}^{2}$. The pellet of 2-SO $\mathbf{O}_{4}$ had a thickness of $60 \mu \mathrm{m}$ and an area of $0.052 \mathrm{~cm}^{2}$. 


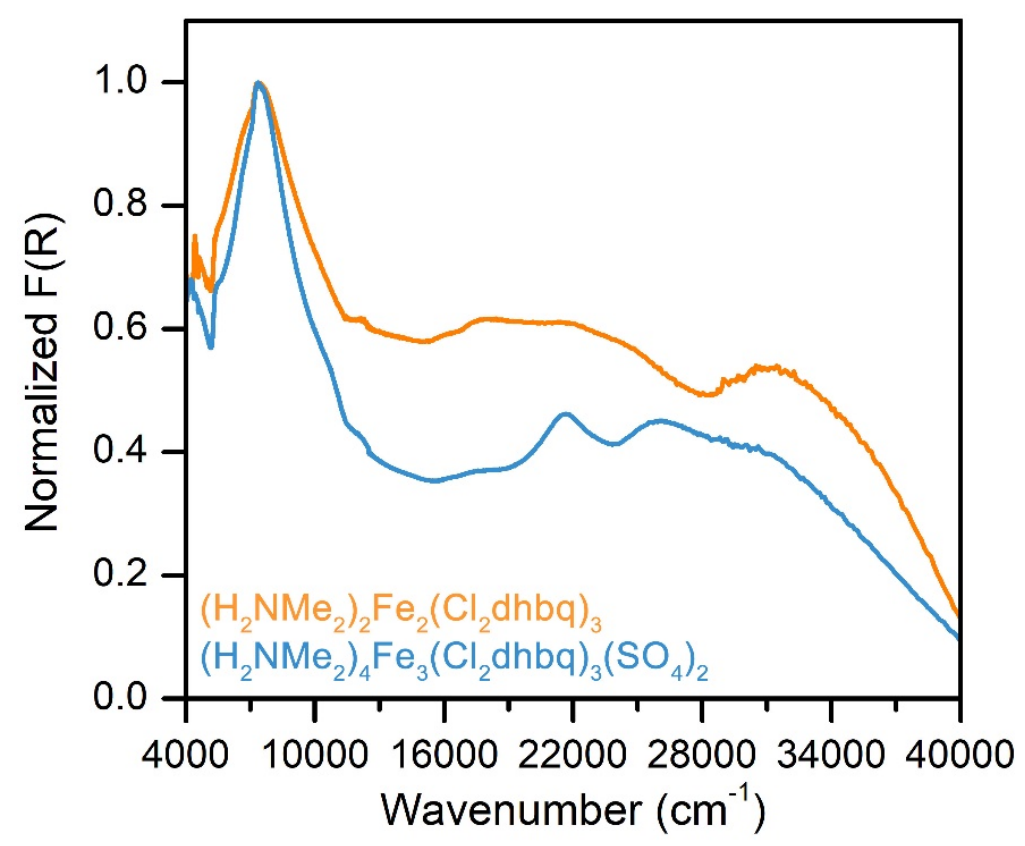

Figure S10. Diffuse reflectance UV-vis-NIR spectra for $\mathbf{1}$ (orange) and 2-SO $\mathbf{S}_{\mathbf{4}}$ (blue). The most intense feature in both spectra is assigned to an intervalence charge transfer transition between ligands of different redox states.
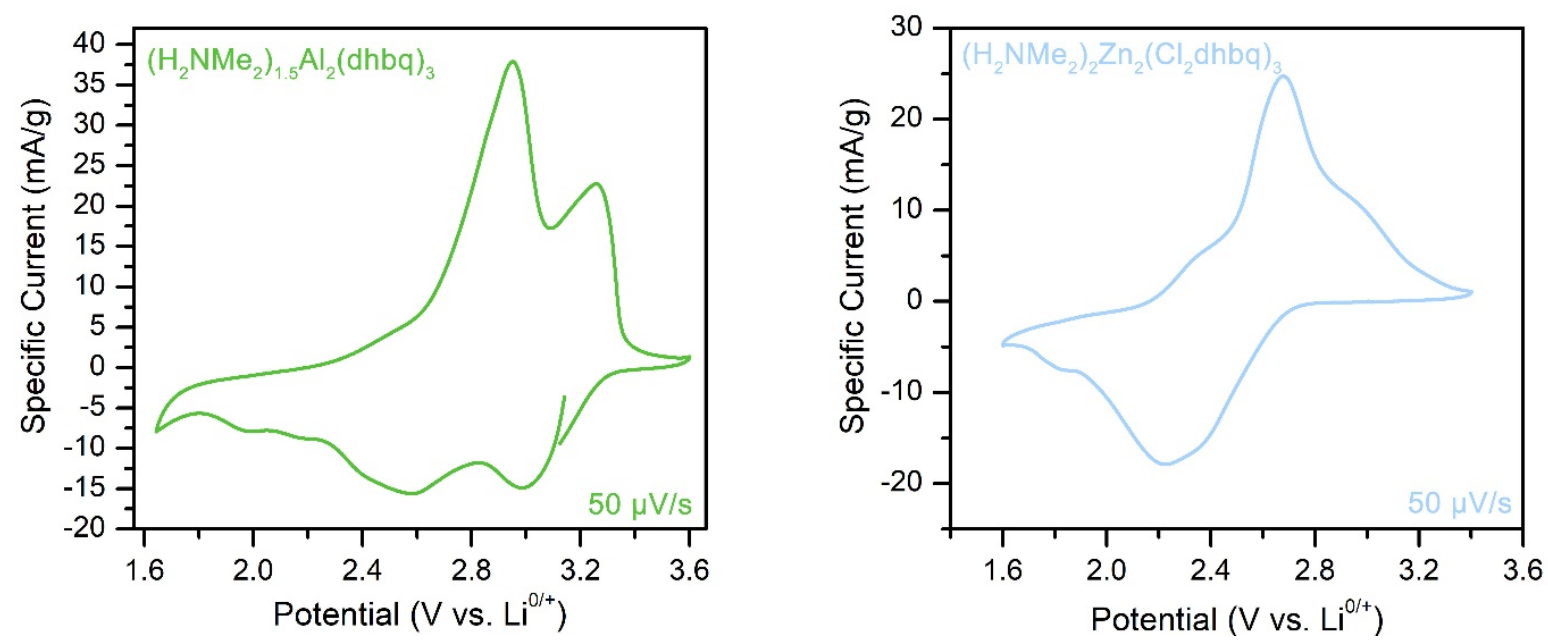

Figure S11. Solid state cyclic voltammograms for $\left(\mathrm{H}_{2} \mathrm{NMe}_{2}\right)_{1.5} \mathrm{Al}_{2}(\mathrm{dhbq})_{3}$ and $\left(\mathrm{H}_{2} \mathrm{NMe}_{2}\right)_{2} \mathrm{Zn}\left(\mathrm{Cl}_{2} \mathrm{hbq}\right)_{3}$ collected at $50 \mu \mathrm{V} / \mathrm{s}$ with a $0.1 \mathrm{M}$ solution of $\mathrm{LiBF}_{4}$ in propylene carbonate as the electrolyte. Both phases are isostructural to $\mathbf{1}$. For both systems, integration of the current yields electrochemical capacities corresponding to roughly one electron per ligand. 


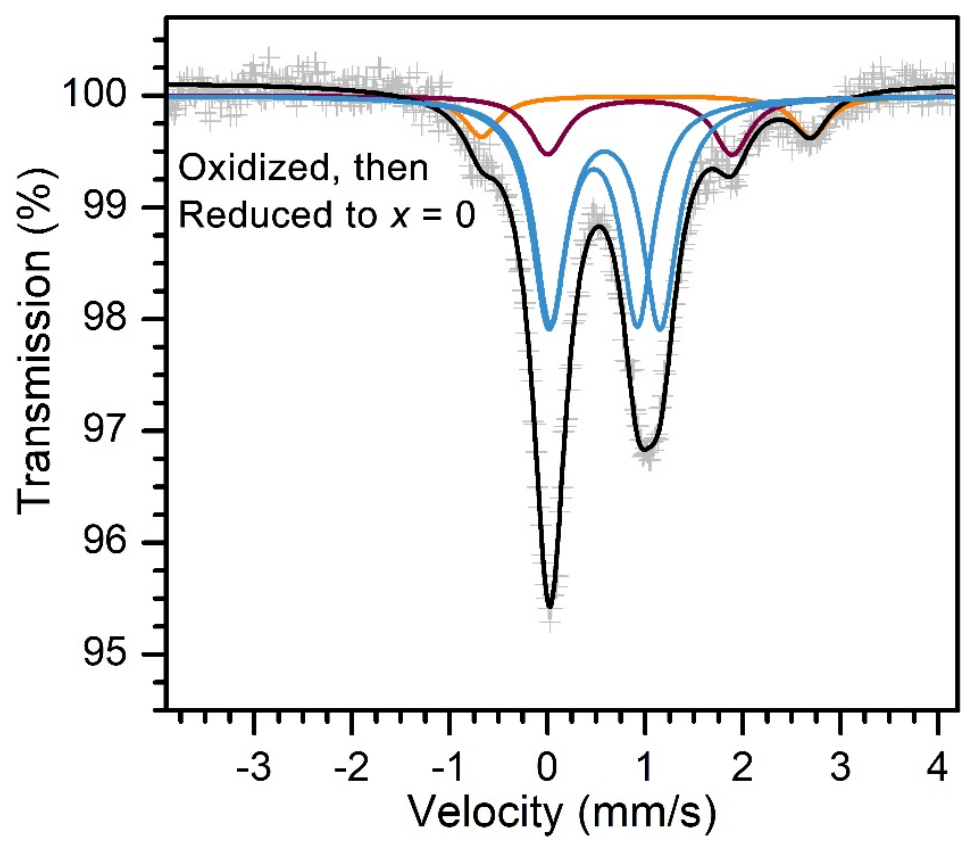

Figure S12. Mössbauer spectrum for a sample of 1 electrochemically oxidized by two electrons then reduced by two electrons to its initial charge state, corresponding to $x=0$ for the chemical formula $\mathrm{Li}_{x}\left(\mathrm{H}_{2} \mathrm{NMe}_{2}\right)_{2} \mathrm{Fe}_{2}\left(\mathrm{Cl}_{2} \mathrm{dhbq}\right)_{3}$. Black, blue and orange lines correspond to the overall fit, fits to high spin $\mathrm{Fe}^{\mathrm{III}}$ sites, and fits to high spin $\mathrm{Fe}^{\mathrm{II}}$ sites, respectively. The dark red line corresponds to a delocalized $\mathrm{Fe}^{\mathrm{II}} / \mathrm{Fe}^{\mathrm{III}}$ site, on the basis of its intermediate isomer shift and quadrupole splitting. The appearance of partial $\mathrm{Fe}^{\mathrm{II}}$ character is likely due to uneven electrochemical reduction. Full fit parameters are listed in Table S3.

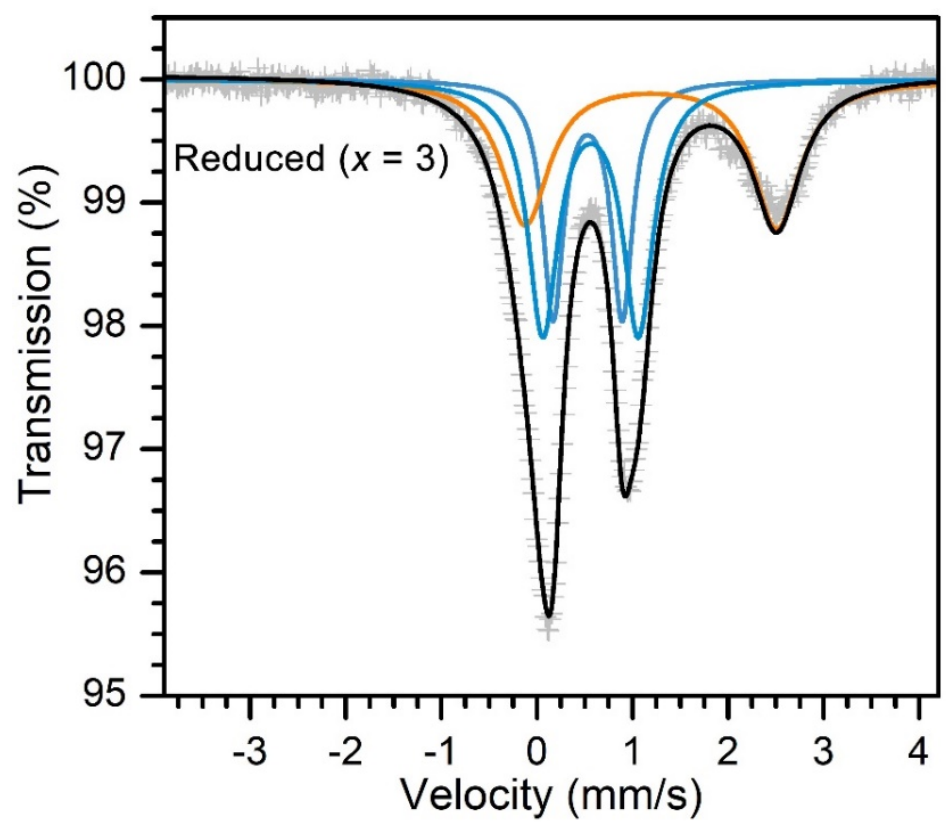

Figure S13. Mössbauer spectrum for a sample of 1 electrochemically reduced by three electrons per formula unit corresponding to $\mathrm{Li}_{x}\left(\mathrm{H}_{2} \mathrm{NMe}_{2}\right)_{2} \mathrm{Fe}_{2}\left(\mathrm{Cl}_{2} \mathrm{dhbq}\right)_{3}$ with $x=3$. Black, blue and orange lines correspond to the overall fit, fits to high spin $\mathrm{Fe}^{\mathrm{III}}$ sites, and fits to high spin $\mathrm{Fe}^{\mathrm{II}}$ sites, respectively. Full fit parameters are listed in Table S3. 
Table S3. Parameters for fits of the Mössbauer spectra of 1 at full oxidation and varying levels of reduction, $\mathrm{Li}_{x}\left(\mathrm{H}_{2} \mathrm{NMe}_{2}\right)_{2} \mathrm{Fe}_{2}\left(\mathrm{Cl}_{2} \mathrm{dhbq}\right)_{3}$ for $x=0-4$. Fits corresponding to high spin $\mathrm{Fe}^{\mathrm{II}}$ sites are shown in orange, fits corresponding to high spin $\mathrm{Fe}^{\mathrm{III}}$ sites are shown in blue, and fits corresponding to intermediate valence sites are shown in dark red. Larger errors are observed for overlapping fits.

\begin{tabular}{lcccc}
\hline Compound & $\begin{array}{c}\delta \\
(\mathrm{mm} / \mathrm{s})\end{array}$ & $\begin{array}{c}\Delta E_{Q} \\
(\mathrm{~mm} / \mathrm{s})\end{array}$ & $\begin{array}{c}\Gamma \\
(\mathrm{mm} / \mathrm{s})\end{array}$ & $\begin{array}{c}\text { Fractional } \\
\text { Area }\end{array}$ \\
\hline $\mathbf{1}$, Oxidized & $0.475(5)$ & $0.75(3)$ & $0.31(2)$ & $0.84(19)$ \\
& $0.489(18)$ & $1.12(9)$ & $0.35(9)$ & $0.16(16)$ \\
& & & & \\
$\mathbf{1}$, Cycled & $0.478(27)$ & $0.89(4)$ & $0.40(4)$ & $0.39(6)$ \\
to $x=0$ & $0.585(13)$ & $1.14(4)$ & $0.43(3)$ & $0.43(9)$ \\
& $0.947(46)$ & $1.88(11)$ & $0.45(9)$ & $0.11(2)$ \\
& $1.012(35)$ & $3.37(5)$ & $0.42(9)$ & $0.07(2)$ \\
$\mathbf{1}, \boldsymbol{x}=\mathbf{2}$ & $0.543(8)$ & $0.76(3)$ & $0.24(5)$ & $0.21(15)$ \\
& $0.563(8)$ & $1.00(7)$ & $0.35(4)$ & $0.42(16)$ \\
& $1.217(14)$ & $2.67(2)$ & $0.64(4)$ & $0.37(2)$ \\
$\mathbf{1}, \boldsymbol{x}=\mathbf{3}$ & $0.530(5)$ & $0.72(2)$ & $0.26(4)$ & $0.27(10)$ \\
& $0.557(8)$ & $1.01(5)$ & $0.38(3)$ & $0.41(11)$ \\
& $1.196(18)$ & $2.62(3)$ & $0.66(4)$ & $0.39(2)$ \\
$\mathbf{1}, x=4$ & $0.535(16)$ & $0.79(2)$ & $0.29(3)$ & $0.42(9)$ \\
& $0.542(8)$ & $1.09(10)$ & $0.34(5)$ & $0.24(9)$ \\
& $1.232(11)$ & $2.80(2)$ & $0.59(4)$ & $0.34(2)$ \\
\hline
\end{tabular}

Table S4. Calculated spin density on $\mathrm{Fe}$ in $\mathbf{1}$ as a function of $U$ for the as-synthesized framework. A value of $U=9 \mathrm{eV}$ comes closest to matching the experimental spin density for a high spin $\mathrm{Fe}^{\mathrm{III}}$ ion.

\begin{tabular}{cc}
\hline$U(\mathrm{eV})$ & $\begin{array}{c}\text { Spin Density } \\
\text { on Fe }\end{array}$ \\
\hline 0 & 3.8 \\
2 & 4.0 \\
4 & 4.1 \\
6 & 4.3 \\
8 & 4.5 \\
9 & 4.7 \\
10 & 15.4 \\
\hline
\end{tabular}


Table S5. Spin density on $\mathrm{Cr}$ in $\left(\mathrm{H}_{2} \mathrm{NMe}_{2}\right)_{2} \mathrm{Cr}_{2}(\mathrm{dhbq})_{3}$ as a function of $U$. At $U=4 \mathrm{eV}$, the calculated spin density matches the experimental value.

\begin{tabular}{cc}
\hline$U(\mathrm{eV})$ & $\begin{array}{c}\text { Spin Density } \\
\text { on Cr }\end{array}$ \\
\hline 0 & 2.5 \\
2 & 2.8 \\
3 & 2.9 \\
4 & 3.0 \\
6 & 3.1 \\
\hline
\end{tabular}

Table S6. Total energy for various $k$-point meshes for as-synthesized 1 with $U=9 \mathrm{eV}$. The total energy for the $1 \times 1 \times 2 k$-point mesh differs by only $3 \mathrm{meV}$ per atom with respect to the higher $k$-point meshes.

\begin{tabular}{cc}
\hline$k$-point Mesh & $\begin{array}{c}\text { Total Energy } \\
(\mathrm{eV})\end{array}$ \\
\hline $1 \times 1 \times 2$ & -272.96 \\
$2 \times 2 \times 2$ & -273.10 \\
$4 \times 4 \times 4$ & -273.10 \\
\hline
\end{tabular}


Table S7. Relative energies of different possible electronic configurations of $\mathbf{1}$ upon simulated reduction using $\mathrm{PBE}+U$. The total magnetization of the unit cell, defined as the number of $\alpha$ electrons minus the number of $\beta$ electrons, is also shown. $\mathrm{L}^{n-}$ corresponds to $\mathrm{Cl}_{2} \mathrm{dhbq}^{n-}$. Attempts to stabilize metal-based reduction for the $(-3)$ framework failed to converge. All listed metal oxidation states correspond to high spin states. Colors are used to group different charge distributions for a single reduction level.

\begin{tabular}{cccccc}
\hline $\begin{array}{c}\text { Unit Cell } \\
\text { Charge }\end{array}$ & $\begin{array}{c}\mathrm{Fe} \\
\text { Configuration }\end{array}$ & $\begin{array}{c}\text { Ligand } \\
\text { Configuration }\end{array}$ & $\begin{array}{c}\text { Total } \\
\text { Magnetization }\end{array}$ & $\begin{array}{c}\text { Absolute } \\
\text { Energy }(\mathrm{eV})\end{array}$ & $\begin{array}{c}\text { Relative } \\
\text { Energy }(\mathrm{eV})\end{array}$ \\
\hline-2 & $\mathrm{Fe}^{\mathrm{III}}{ }_{2}$ & $\left(\mathrm{~L}^{2-}\right)\left(\mathrm{L}^{3-}\right)_{2}$ & 8 & -272.96 & 0.00 \\
-3 & $\mathrm{Fe}^{\mathrm{III}}{ }_{2}$ & $\left(\mathrm{~L}^{3-}\right)_{3}$ & 7 & -275.65 & 0.00 \\
-4 & $\mathrm{Fe}^{\mathrm{III}}{ }_{2}$ & $\left(\mathrm{~L}^{3-}\right)_{2}\left(\mathrm{~L}^{4-}\right)$ & 8 & -276.65 & 0.99 \\
-4 & $\mathrm{Fe}^{\mathrm{II}} \mathrm{Fe}^{\mathrm{III}}$ & $\left(\mathrm{L}^{3-}\right)_{3}$ & 6 & -277.63 & 0.00 \\
-5 & $\mathrm{Fe}^{\mathrm{III}}{ }_{2}$ & $\left(\mathrm{~L}^{3-}\right)\left(\mathrm{L}^{4-}\right)_{2}$ & 9 & -277.68 & 1.75 \\
-5 & $\mathrm{Fe}^{\mathrm{II}} \mathrm{Fe}^{\mathrm{III}}$ & $\left(\mathrm{L}^{3-}\right)_{2}\left(\mathrm{~L}^{4-}\right)$ & 7 & -278.75 & 0.68 \\
-5 & $\mathrm{Fe}^{\mathrm{II}}{ }_{2}$ & $\left(\mathrm{~L}^{3-}\right)_{3}$ & 5 & -279.43 & 0.00 \\
-6 & $\mathrm{Fe}^{\mathrm{III}}{ }_{2}$ & $\left(\mathrm{~L}^{4-}\right)_{3}$ & 10 & -278.57 & 1.82 \\
-6 & $\mathrm{Fe}^{\mathrm{II}} \mathrm{Fe}^{\mathrm{III}}$ & $\left(\mathrm{L}^{3-}\right)\left(\mathrm{L}^{4-}\right)_{2}$ & 8 & -279.56 & 0.83 \\
-6 & $\mathrm{Fe}^{\mathrm{II}}{ }_{2}$ & $\left(\mathrm{~L}^{3-}\right)_{2}\left(\mathrm{~L}^{4-}\right)$ & 6 & -280.39 & 0.00 \\
\hline
\end{tabular}

Table S8. Spin density on Fe ions in as-synthesized 1 generated from the HSE06 functional with varying levels of HF exchange. Geometries were optimized using PBE $+U$ calculations, and HSE06 calculations were performed as single point calculations at the $\Gamma$ point. The calculation with $100 \% \mathrm{HF}$ exchange comes closest to matching the experimental spin density of 5 for high spin $\mathrm{Fe}^{\mathrm{III}}$.

\begin{tabular}{cc}
\hline $\begin{array}{c}\text { HF Exchange } \\
(\%)\end{array}$ & $\begin{array}{c}\text { Spin Density } \\
\text { on Fe }\end{array}$ \\
\hline 20 & 4.1 \\
40 & 4.2 \\
60 & 4.4 \\
80 & 4.5 \\
100 & 4.6 \\
\hline
\end{tabular}


Table S9. Relative energies of different possible electronic configurations of $\mathbf{1}$ upon simulated reduction using HSE06 with 100\% HF exchange. The total magnetization of the unit cell, defined as the number of $\alpha$ electrons minus the number of $\beta$ electrons, is also shown. $\mathrm{L}^{n-}$ corresponds to $\mathrm{Cl}_{2} \mathrm{dhbq}^{n-}$. Attempts to stabilize metal-based reduction for the $(-3)$ framework failed to converge. All listed metal oxidation states correspond to high spin states. Colors are used to group different charge distributions for a single reduction level. Note that the most stable configuration for the $(-5)$ charge state differs from the one observed using $\mathrm{PBE}+U$.

\begin{tabular}{cccccc}
\hline $\begin{array}{c}\text { Unit Cell } \\
\text { Charge }\end{array}$ & $\begin{array}{c}\mathrm{Fe} \\
\text { Configuration }\end{array}$ & $\begin{array}{c}\text { Ligand } \\
\text { Configuration }\end{array}$ & $\begin{array}{c}\text { Total } \\
\text { Magnetization }\end{array}$ & $\begin{array}{c}\text { Absolute } \\
\text { Energy }(\mathrm{eV})\end{array}$ & $\begin{array}{c}\text { Relative } \\
\text { Energy }(\mathrm{eV})\end{array}$ \\
\hline-2 & $\mathrm{Fe}^{\mathrm{III}}{ }_{2}$ & $\left(\mathrm{~L}^{2-}\right)\left(\mathrm{L}^{3-}\right)_{2}$ & 8 & -545.47 & 0.00 \\
-3 & $\mathrm{Fe}^{\mathrm{III}}{ }_{2}$ & $\left(\mathrm{~L}^{3-}\right)_{3}$ & 7 & -549.02 & 0.00 \\
-4 & $\mathrm{Fe}^{\mathrm{III}}{ }_{2}$ & $\left(\mathrm{~L}^{3-}\right)_{2}\left(\mathrm{~L}^{4-}\right)$ & 8 & -549.23 & 0.39 \\
-4 & $\mathrm{Fe}^{\mathrm{II}} \mathrm{Fe}^{\mathrm{III}}$ & $\left(\mathrm{L}^{3-}\right)_{3}$ & 6 & -549.62 & 0.00 \\
-5 & $\mathrm{Fe}^{\mathrm{III}}{ }_{2}$ & $\left(\mathrm{~L}^{3-}\right)\left(\mathrm{L}^{4-}\right)_{2}$ & 9 & -549.78 & 1.01 \\
-5 & $\mathrm{Fe}^{\mathrm{II}} \mathrm{Fe}^{\mathrm{III}}$ & $\left(\mathrm{L}^{3-}\right)_{2}\left(\mathrm{~L}^{4-}\right)$ & 7 & -550.80 & 0.00 \\
-5 & $\mathrm{Fe}_{2}$ & $\left(\mathrm{~L}^{3-}\right)_{3}$ & 5 & -550.02 & 0.78 \\
-6 & $\mathrm{Fe}^{\mathrm{III}}{ }_{2}$ & $\left(\mathrm{~L}^{4-}\right)_{3}$ & 10 & -550.89 & 0.34 \\
-6 & $\mathrm{Fe}^{\mathrm{II}} \mathrm{Fe}^{\mathrm{III}}$ & $\left(\mathrm{L}^{3-}\right)\left(\mathrm{L}^{4-}\right)_{2}$ & 8 & -550.82 & 0.41 \\
-6 & $\mathrm{Fe}_{2}$ & $\left(\mathrm{~L}^{3-}\right)_{2}\left(\mathrm{~L}^{4-}\right)$ & 6 & -551.23 & 0.00 \\
\hline
\end{tabular}

Table S10. Absolute energies of chromium phase upon simulated reduction using $\mathrm{PBE}+U$. The total magnetization of the unit cell, defined as the number of $\alpha$ electrons minus the number of $\beta$ electrons, is also shown. $\mathrm{L}^{n-}$ corresponds to $\mathrm{Cl}_{2} \mathrm{dhbq}^{n-}$. All listed metal oxidation states correspond to high spin states. No configurations containing $\mathrm{Cr}^{\mathrm{II}}$ were observed computationally, so only one configuration was found for each level of reduction. Colors are used to indicate different reduction levels.

\begin{tabular}{ccccc}
\hline $\begin{array}{c}\text { Unit Cell } \\
\text { Charge }\end{array}$ & $\begin{array}{c}\mathrm{Cr} \\
\text { Configuration }\end{array}$ & $\begin{array}{c}\text { Ligand } \\
\text { Configuration }\end{array}$ & $\begin{array}{c}\text { Total } \\
\text { Magnetization }\end{array}$ & $\begin{array}{c}\text { Absolute } \\
\text { Energy }(\mathrm{eV})\end{array}$ \\
\hline-2 & $\mathrm{Cr}^{\mathrm{III}}{ }_{2}$ & $\left(\mathrm{~L}^{2-}\right)\left(\mathrm{L}^{3-}\right)_{2}$ & 4 & -289.70 \\
-3 & $\mathrm{Cr}^{\mathrm{III}}{ }_{2}$ & $\left(\mathrm{~L}^{3-}\right)_{3}$ & 3 & -291.41 \\
-4 & $\mathrm{Cr}^{\mathrm{III}}{ }_{2}$ & $\left(\mathrm{~L}^{3-}\right)_{2}\left(\mathrm{~L}^{4-}\right)$ & 4 & -292.38 \\
-5 & $\mathrm{Cr}^{\mathrm{III}}{ }_{2}$ & $\left(\mathrm{~L}^{3-}\right)\left(\mathrm{L}^{4-}\right)_{2}$ & 5 & -293.42 \\
-6 & $\mathrm{Cr}^{\mathrm{III}}{ }_{2}$ & $\left(\mathrm{~L}^{4-}\right)_{3}$ & 6 & -294.14 \\
\hline
\end{tabular}




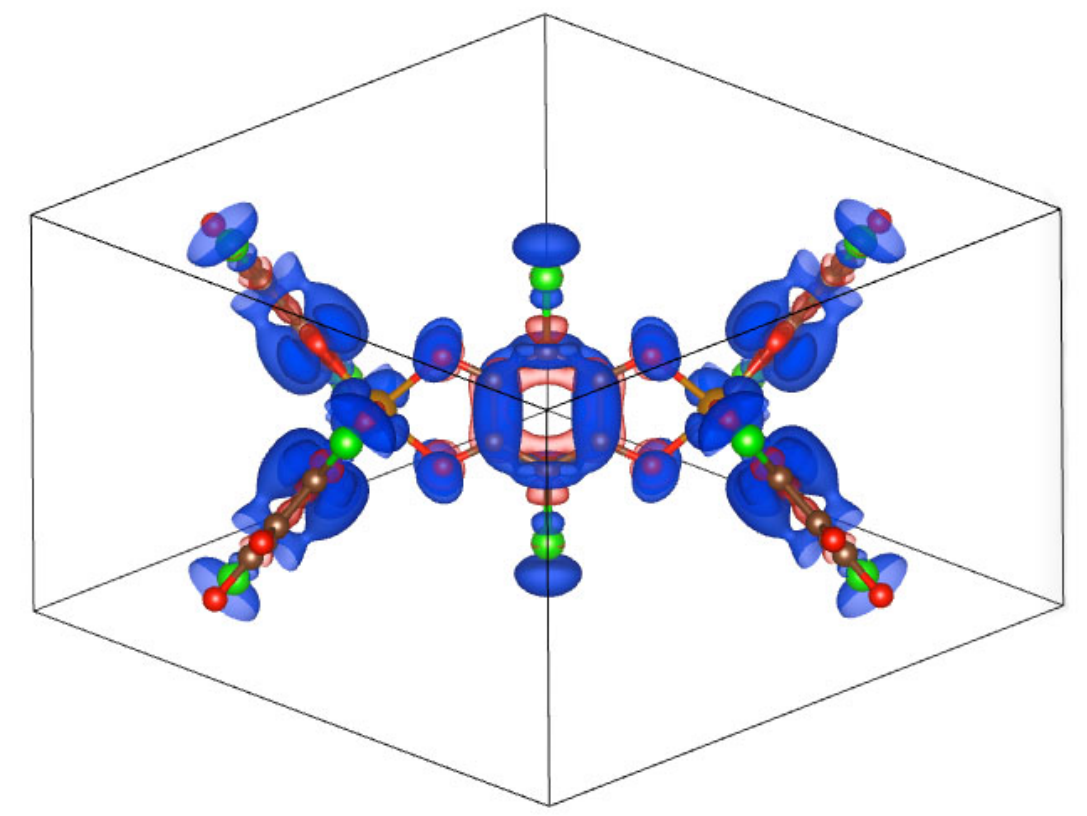

Figure S14. Isosurface of the charge density difference upon reduction of $\mathbf{1}$ from the $(-3)$ charge to the $(-4)$ charge, as calculated with $\mathrm{PBE}+U$, and assuming a ligand-centered reduction. For both levels of reduction, the geometry optimized for the $(-4)$ charge state was used. Blue and red surfaces represent accumulation and depletion of electron density (respectively). Note that charge accumulation profile is similar to the LUMO of $\mathrm{dhbq}^{2-}$ (the HOMO of $\left.\mathrm{dhbq}^{4-}\right){ }^{13}$

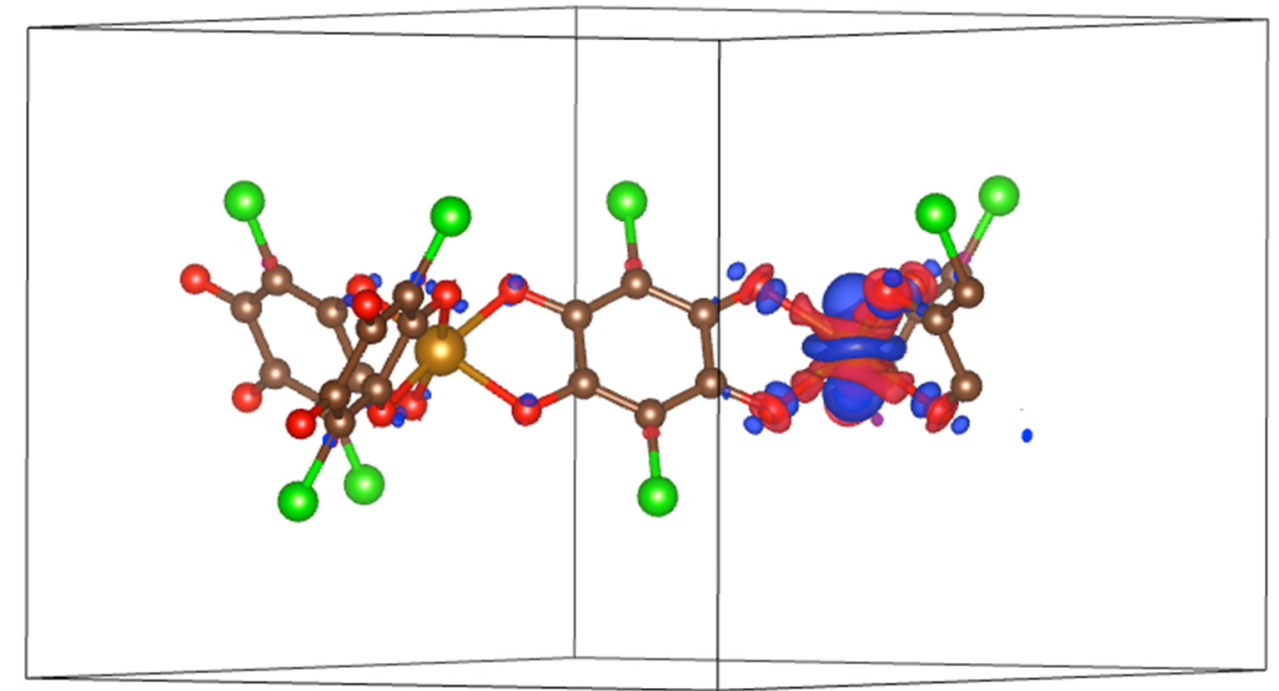

Figure S15. Isosurface of the charge density difference upon reduction of 1 from the $(-3)$ charge to the $(-4)$ charge, as calculated with $\mathrm{PBE}+U$, and assuming a metal-centered reduction. For both levels of reduction, the geometry optimized for the $(-4)$ charge state was used. Blue and red surfaces represent accumulation and depletion of electron density (respectively). Note that charge accumulation profile is similar to the $\mathrm{d}_{z 2}$ orbital of $\mathrm{Fe}$, which should be lowest in energy for this coordination geometry. The charge density is localized on a single $\mathrm{Fe}$ site, as is observed in experiment. 


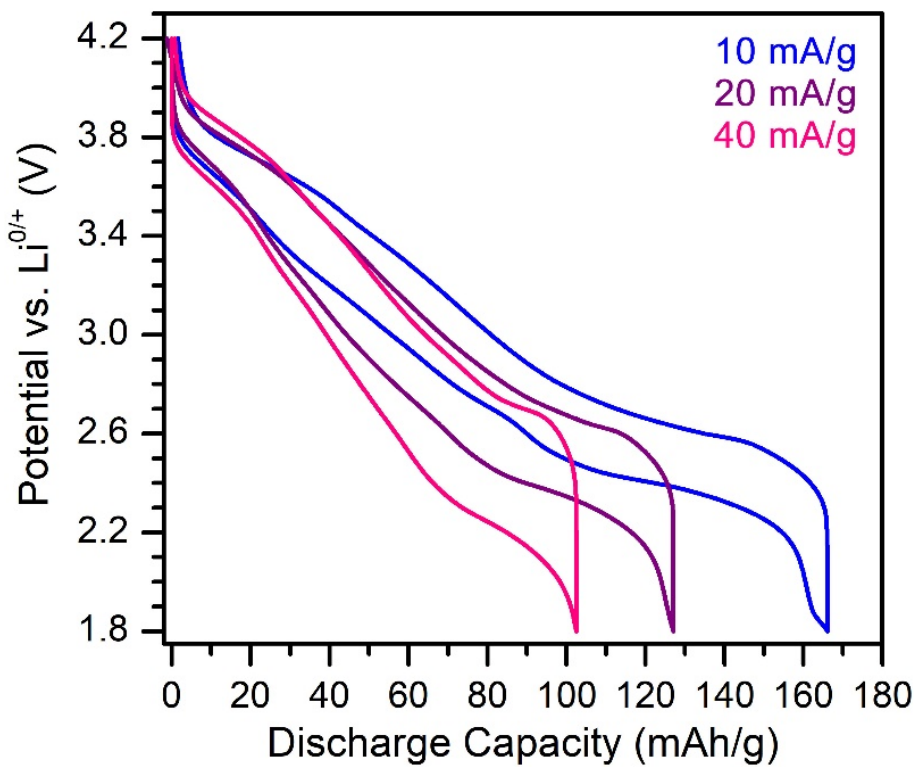

Figure S16. Charge and discharge curves for $\mathbf{2}-\mathrm{SO}_{4}$ at charging rates up to $40 \mathrm{~mA} / \mathrm{g}$.
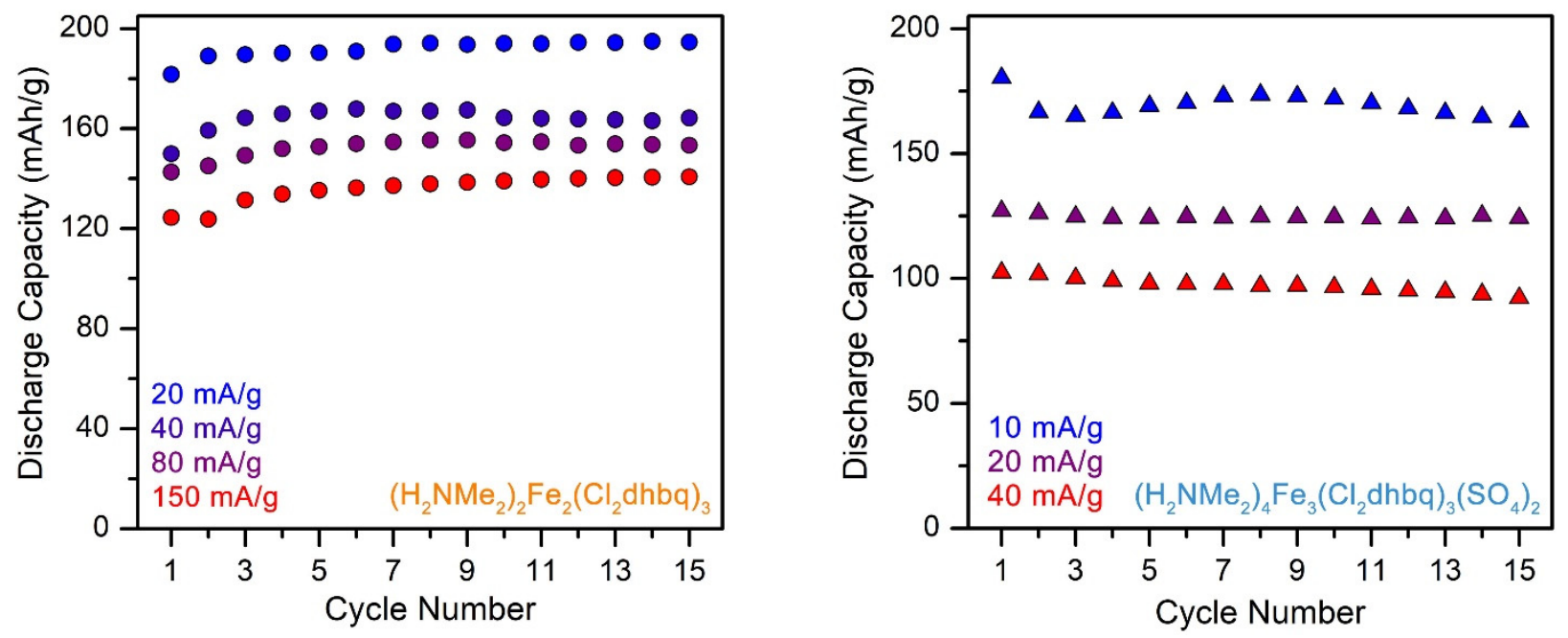

Figure S17. Discharge capacities over 15 cycles for $\mathbf{1}$ (left) and 2-SO 4 (right) at different charging rates. Data were collected with a $0.1 \mathrm{M} \mathrm{LiBF}_{4}$ propylene carbonate solution as the electrolyte. 


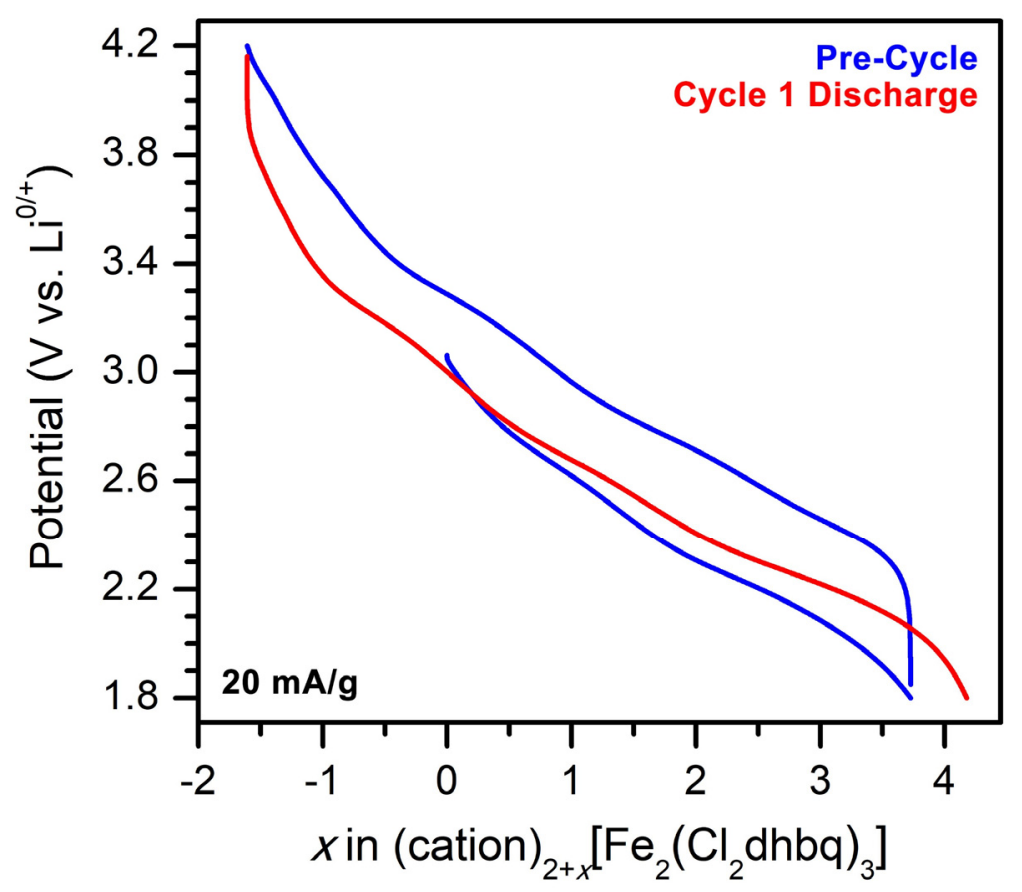

Figure S18. Charge and discharge profiles for the pre-cycle and first cycle discharge of $\mathbf{1}$ at $20 \mathrm{~mA} / \mathrm{g}$. No irreversible capacity is observed during this pre-cycle for any charging rate. 


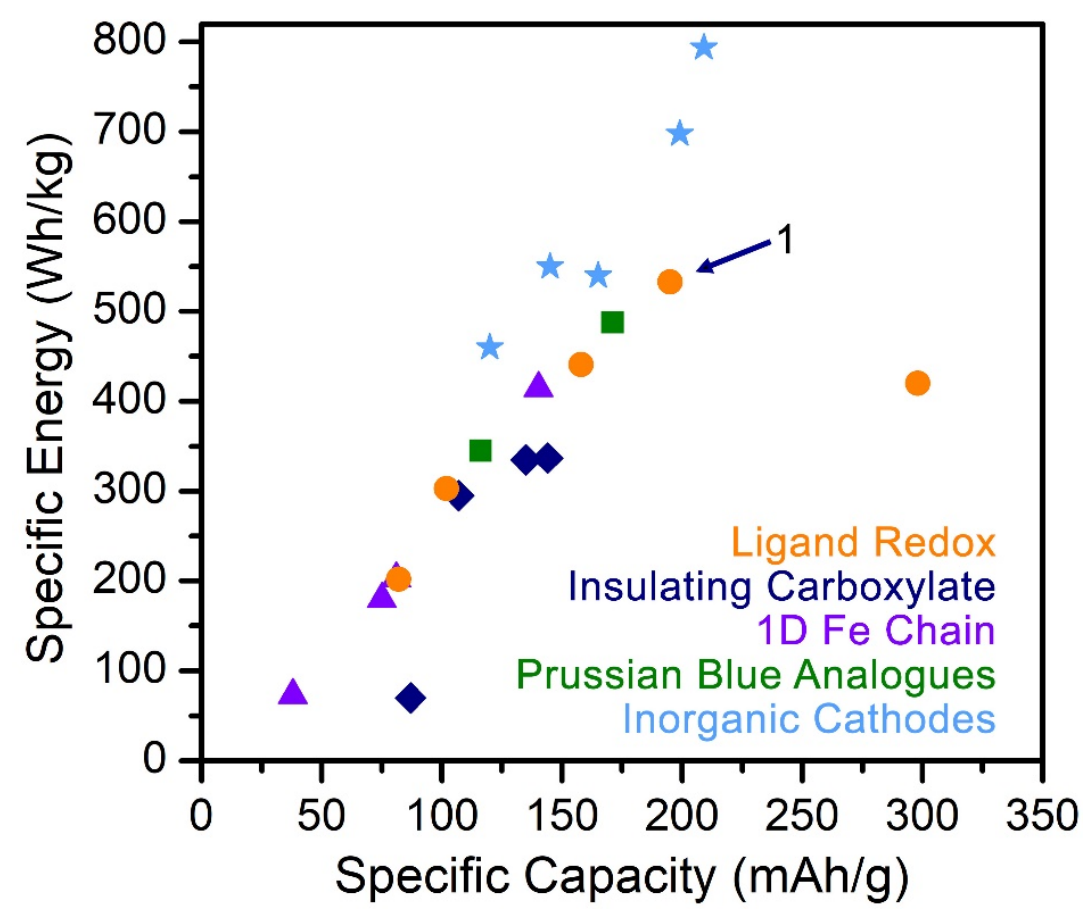

Figure S19. Comparison of specific capacities and specific energies for reported framework-based cathode materials and commercialized inorganic cathode materials. Framework-based cathodes are separated into four categories: (1) Frameworks utilizing ligand redox activity (orange circles), (2) Redox-active insulating carboxylate frameworks (navy diamonds), (3) Frameworks containing one-dimensional chains of redoxactive iron ions (purple triangles), and (4) Prussian blue analogues (green squares). Specific energies were obtained from discharge curves at the slowest reported charging rate. In cases where the first discharge cycle showed a substantial contribution from SEI formation, the second cycle was used. For frameworks evaluated as sodium-ion cathode materials, specific energies were obtained by shifting the voltage of the discharge curve to account for the potential difference between sodium and lithium. A full list of the materials shown here is provided in Table S11. Note that amorphous framework materials and dense coordination solids (materials lacking a non-framework void) are not depicted in this graph. 
Table S11. Details for the cathode materials displayed in Figure S16. Shadings correspond to the classifications used in Figure S16: (1) Inorganic cathodes (white), (2) Frameworks utilizing ligand redox activity (orange), (3) Frameworks containing one-dimensional chains of redox-active iron ions (purple), (4) Prussian blue analogues (green), and (5) Redox-active insulating carboxylate frameworks (blue). Ligand abbreviations: $\mathrm{Cl}_{2} \mathrm{dhbq}^{2-}=2,5$-dichloro-3,6-dihydroxybenzoquinone; hib $^{3-}=$ hexaiminobenzene; bdc ${ }^{2-}=$ 1,4-benzenedicarboxylate; $\mathrm{tca}^{3-}=$ tricarboxylatotriphenylamine; $2,7-\mathrm{aqdc}^{2-}=2,7-$ anthroquinonedicarboxylate; 2,6-aqde ${ }^{2-}=2,6$-anthroquinonedicarboxylate; btc $^{3-}=1,3,5-$ benzenetricarboxylate. $*=$ Specific energy was calculated using the sodium discharge curve and adjusting the voltage to account for the potential difference between sodium and lithium.

\begin{tabular}{|c|c|c|c|}
\hline Compound & $\begin{array}{l}\text { Specific Capacity } \\
(\mathrm{mAh} / \mathrm{g})\end{array}$ & $\begin{array}{l}\text { Specific Energy } \\
\quad(\mathrm{Wh} / \mathrm{kg})\end{array}$ & Reference \\
\hline $\mathrm{LiFe}\left(\mathrm{PO}_{4}\right)$ & 165 & 540 & 14 \\
\hline $\mathrm{LiCoO}_{2}$ & 145 & 546 & 14 \\
\hline $\mathrm{LiMn}_{2} \mathrm{O}_{4}$ & 120 & 460 & 14 \\
\hline $\mathrm{LiNi}_{x} \mathrm{Co}_{y} \mathrm{Al}_{z} \mathrm{O}_{2}$ & 199 & 698 & 14 \\
\hline $\mathrm{LiNi}_{x} \mathrm{Mn}_{y} \mathrm{Co}_{z} \mathrm{O}_{2}$ & 209 & 794 & 15 \\
\hline 1 & 195 & 533 & This work \\
\hline$\left(\mathrm{NBu}_{4}\right) \mathrm{MnCr}\left(\mathrm{Cl}_{2} \mathrm{dhbq}\right)_{3}$ & 82 & 202 & 16 \\
\hline $\mathrm{Co}_{3}(\mathrm{hib})_{2}$ & 298 & $420 *$ & 17 \\
\hline $\mathrm{Ni}_{3}(\mathrm{hib})_{2}$ & 158 & 441 & 18 \\
\hline $\mathrm{Cu}_{3}(\mathrm{tca})_{2}$ & 102 & 303 & 19 \\
\hline $\mathrm{Fe}(\mathrm{OH})(\mathrm{bdc})(\mathrm{MIL}-53)$ & 75 & 180 & 20 \\
\hline $\mathrm{Fe}(\mathrm{OH})(\mathrm{bdc})(\mathrm{MIL}-68)$ & 38 & 73 & 21 \\
\hline $\mathrm{Fe}_{2}(\mathrm{dobpdc})$ & 140 & 415 & 22 \\
\hline $\mathrm{Fe}\left[\mathrm{Fe}(\mathrm{CN})_{6}\right]$ & 116 & 345 & 23 \\
\hline $\mathrm{K}_{1.72} \mathrm{Mn}\left[\mathrm{Mn}(\mathrm{CN})_{6}\right]_{0.93}$ & 171 & 488 & 24 \\
\hline$\left(\mathrm{Fe}_{3} \mathrm{O}\right)(\mathrm{bdc})_{3} \mathrm{Cl}$ & 107 & 295 & 25 \\
\hline $\mathrm{Cu}_{3}(2,7-\mathrm{aqdc})_{2}$ & 135 & 335 & 26 \\
\hline $\mathrm{Mn}_{7}(2,7-\mathrm{aqdc})_{6}(2,6-\mathrm{aqdc})$ & 144 & 337 & 27 \\
\hline $\mathrm{CoLi}(\mathrm{btc})$ & 87 & 70 & 28 \\
\hline
\end{tabular}

\section{References}

1. Jeon Ie, R.; Negru, B.; Van Duyne, R. P.; Harris, T. D. A 2D Semiquinone Radical-Containing Microporous Magnet with Solvent-Induced Switching from Tc $=26$ to 80 K. J. Am. Chem. Soc. 2015, 137, 15699-15702.

2. Halis, S.; Inge, A. K.; Dehning, N.; Weyrich, T.; Reinsch, H.; Stock, N. Dihydroxybenzoquinone as Linker for the Synthesis of Permanently Porous Aluminum Metal-Organic Frameworks. Inorg. Chem. 2016, $55,7425-7431$.

3. Prisecaru, I. WMOSS4 Mössbauer Spectral Analysis Software, www.wmoss.org, 2009-2013. 
4.(a) Coelho, A. A. Indexing of powder diffraction patterns by iterative use of singular value decomposition. J. Appl. Crystallogr. 2003, 36, 86-95; (b) Coelho, A. A. "TOPAS-Academic, version 4.1" 2007.

5.SAINT and APEX 2 Software for CCD Diffractometers, Bruker Analytical X-ray Systems, Inc.: Madison, WI, 2000.

6. Sheldrick, G. M. SADABS, Bruker Analytical X-ray Systems, Inc.: Madison, WI, 2014.

7. Sheldrick, G. M. SHELXT - integrated space-group and crystal-structure determination. Acta Cryst. A 2015, 71, 3-8.

8. (a) Sheldrick, G. M. A short history of SHELX. Acta Cryst. A 2008, 64, 112-122; (b) Sheldrick, G. M. SHELXL, University of Gottingen: Germany, 2014; (c) Sheldrick, G. M. "Crystal structure refinement with SHELXL" Acta Cryst. C 2015, 71, 3-8.

9. Dolomanov, O. V.; Bourhis, L. J.; Gildea, R. J.; Howard, J. A. K.; Puschmann, H. OLEX2: a complete structure solution, refinement and analysis program. J. Appl. Crystallogr. 2009, 42, 339-341.

10. Spek, A. L. PLATON SQUEEZE: a tool for the calculation of the disordered solvent contribution to the calculated structure factors. Acta Cryst. C 2015, 71, 9-18.

11. Spek, A. L. Single-crystal structure validation with the program PLATON. J. Appl. Crystallogr. 2003, $36,7-13$.

12. Darago, L. E.; Aubrey, M. L.; Yu, C. J.; Gonzalez, M. I.; Long, J. R. Electronic Conductivity, Ferrimagnetic Ordering, and Reductive Insertion Mediated by Organic Mixed-Valence in a Ferric Semiquinoid Metal-Organic Framework. J. Am. Chem. Soc. 2015, 137, 15703-15711.

13.Ward, M. D. A Dinuclear Ruthenium(II) Complex with the Dianion of 2,5-Dihydroxy-1,4benzoquinone as Bridging Ligand. Redox, Spectroscopic, and Mixed-Valence Properties. Inorg. Chem. 1996, 35, 1712-1714.

14.Nitta, N.; Wu, F.; Lee, J. T.; Yushin, G. Li-ion battery materials: present and future. Mater. Today 2015, $18,252-264$.

15. Shaju, K. M.; Bruce, P. G. Macroporous $\mathrm{Li}\left(\mathrm{Ni}_{1 / 3} \mathrm{Co}_{1 / 3} \mathrm{Mn}_{1 / 3}\right) \mathrm{O}_{2}$ : A High-Power and High-Energy Cathode for Rechargeable Lithium-Ion Batteries. Adv. Mater. 2006, 18, 2330-2334.

16. Taniguchi, K.; Chen, J.; Sekine, Y.; Miyasaka, H. Magnetic Phase Switching in a Tetraoxolene-Bridged Honeycomb Ferrimagnet Using a Lithium Ion Battery System. Chem. Mater. 2017, 29, 10053-10059.

17.Park, J.; Lee, M.; Feng, D.; Huang, Z.; Hinckley, A. C.; Yakovenko, A.; Zou, X.; Cui, Y.; Bao, Z. Stabilization of Hexaaminobenzene in a 2D Conductive Metal-Organic Framework for High Power Sodium Storage. J. Am. Chem. Soc. 2018, 140, 10315-10323. 
18.Wada, K.; Sakaushi, K.; Sasaki, S.; Nishihara, H. Multielectron-Transfer-based Rechargeable Energy Storage of Two-Dimensional Coordination Frameworks with Non-Innocent Ligands. Angew. Chem. Int. Ed. 2018, 57, 8886-8890.

19.Peng, Z.; Yi, X.; Liu, Z.; Shang, J.; Wang, D. Triphenylamine-Based Metal-Organic Frameworks as Cathode Materials in Lithium-Ion Batteries with Coexistence of Redox Active Sites, High Working Voltage, and High Rate Stability. ACS Appl. Mater. Interfaces 2016, 8, 14578-14585.

20.Ferey, G.; Millange, F.; Morcrette, M.; Serre, C.; Doublet, M. L.; Greneche, J. M.; Tarascon, J. M. Mixed-valence $\mathrm{Li} / \mathrm{Fe}$-based metal-organic frameworks with both reversible redox and sorption properties. Angew. Chem. Int. Ed. 2007, 46, 3259-3263.

21.Fateeva, A.; Horcajada, P.; Devic, T.; Serre, C.; Marrot, J.; Grenèche, J.-M.; Morcrette, M.; Tarascon, J.-M.; Maurin, G.; Férey, G. Synthesis, Structure, Characterization, and Redox Properties of the Porous MIL-68(Fe) Solid. Eur. J. Inorg. Chem. 2010, 3789-3794.

22.Aubrey, M. L.; Long, J. R. A Dual-Ion Battery Cathode via Oxidative Insertion of Anions in a MetalOrganic Framework. J. Am. Chem. Soc. 2015, 137, 13594-13602.

23.Shen, L.; Wang, Z.; Chen, L. Prussian blues as a cathode material for lithium ion batteries. Chem. Eur. J. 2014, 20, 12559-12562.

24.Asakura, D.; Okubo, M.; Mizuno, Y.; Kudo, T.; Zhou, H.; Ikedo, K.; Mizokawa, T.; Okazawa, A.; Kojima, N. Fabrication of a Cyanide-Bridged Coordination Polymer Electrode for Enhanced Electrochemical Ion Storage Ability. J. Phys. Chem. C 2012, 116, 8364-8369.

25.Shin, J.; Kim, M.; Cirera, J.; Chen, S.; Halder, G. J.; Yersak, T. A.; Paesani, F.; Cohen, S. M.; Meng, Y. S. MIL-101(Fe) as a lithium-ion battery electrode material: a relaxation and intercalation mechanism during lithium insertion. J. Mater. Chem. A 2015, 3, 4738-4744.

26.Zhang, Z.; Yoshikawa, H.; Awaga, K. Monitoring the solid-state electrochemistry of Cu(2,7-AQDC) (AQDC $=$ anthraquinone dicarboxylate) in a lithium battery: coexistence of metal and ligand redox activities in a metal-organic framework. J. Am. Chem. Soc. 2014, 136, 16112-16115.

27.Zhang, Z.; Yoshikawa, H.; Awaga, K. Discovery of a "Bipolar Charging” Mechanism in the Solid-State Electrochemical Process of a Flexible Metal-Organic Framework. Chem. Mater. 2016, 28, 1298-1303.

28.Du, Z. Q.; Li, Y. P.; Wang, X. X.; Wang, J.; Zhai, Q. G. Enhanced electrochemical performance of LiCo-BTC ternary metal-organic frameworks as cathode materials for lithium-ion batteries. Dalton Trans. 2019, 48, 2013-2018. 
1. Jeon Ie, R.; Negru, B.; Van Duyne, R. P.; Harris, T. D. "A 2D Semiquinone RadicalContaining Microporous Magnet with Solvent-Induced Switching from Tc $=26$ to $80 \mathrm{K"} \mathrm{J.} \mathrm{Am}$. Chem. Soc. 2015, 137, 15699-15702.

2. Halis, S.; Inge, A. K.; Dehning, N.; Weyrich, T.; Reinsch, H.; Stock, N.

"Dihydroxybenzoquinone as Linker for the Synthesis of Permanently Porous Aluminum MetalOrganic Frameworks" Inorg. Chem. 2016, 55, 7425-7431.

3. Prisecaru, I. WMOSS4 Mössbauer Spectral Analysis Software, www.wmoss.org, 2009-2013. 4. (a) Coelho, A. A. "Indexing of powder diffraction patterns by iterative use of singular value decomposition" Journal of Applied Crystallography 2003, 36, 86-95; (b) Coelho, A. A. "TOPAS-Academic, version 4.1" 2007.

5. SAINT and APEX 2 Software for CCD Diffractometers, Bruker Analytical X-ray Systems, Inc.: Madison, WI, 2000.

6. Sheldrick, G. M. SADABS, Bruker Analytical X-ray Systems, Inc.: Madison, WI, 2014.

7. Sheldrick, G. M. "SHELXT - integrated space-group and crystal-structure determination" Acta crystallographica. Section A, Foundations and advances 2015, 71, 3-8.

8. (a) Sheldrick, G. M. "A short history of SHELX" Acta crystallographica. Section A, Foundations of crystallography 2008, 64, 112-122; (b) Sheldrick, G. M. SHELXL, University of Gottingen: Germany, 2014; (c) Sheldrick, G. M. "Crystal structure refinement with SHELXL" Acta crystallographica. Section C, Structural chemistry 2015, 71, 3-8.

9. Dolomanov, O. V.; Bourhis, L. J.; Gildea, R. J.; Howard, J. A. K.; Puschmann, H. "OLEX2: a complete structure solution, refinement and analysis program" Journal of Applied Crystallography 2009, 42, 339-341.

10. Spek, A. L. "PLATON SQUEEZE: a tool for the calculation of the disordered solvent contribution to the calculated structure factors" Acta crystallographica. Section C, Structural chemistry 2015, 71, 9-18.

11. Spek, A. L. "Single-crystal structure validation with the programPLATON" Journal of Applied Crystallography 2003, 36, 7-13.

12. Darago, L. E.; Aubrey, M. L.; Yu, C. J.; Gonzalez, M. I.; Long, J. R. "Electronic

Conductivity, Ferrimagnetic Ordering, and Reductive Insertion Mediated by Organic Mixed-

Valence in a Ferric Semiquinoid Metal-Organic Framework" J. Am. Chem. Soc. 2015, 137, 15703-15711.

13. Ward, M. D. "A Dinuclear Ruthenium(II) Complex with the Dianion of 2,5-Dihydroxy-1,4benzoquinone as Bridging Ligand. Redox, Spectroscopic, and Mixed-Valence Properties" Inorg. Chem. 1996, 35, 1712-1714.

14. Nitta, N.; Wu, F.; Lee, J. T.; Yushin, G. "Li-ion battery materials: present and future" Materials Today 2015, 18, 252-264.

15. Shaju, K. M.; Bruce, P. G. "Macroporous Li(Ni1/3Co1/3Mn1/3)O2: A High-Power and High-Energy Cathode for Rechargeable Lithium Batteries" Adv. Mater. 2006, 18, 2330-2334. 16. Taniguchi, K.; Chen, J.; Sekine, Y.; Miyasaka, H. "Magnetic Phase Switching in a Tetraoxolene-Bridged Honeycomb Ferrimagnet Using a Lithium Ion Battery System" Chem. Mater. 2017, 29, 10053-10059. 
17. Park, J.; Lee, M.; Feng, D.; Huang, Z.; Hinckley, A. C.; Yakovenko, A.; Zou, X.; Cui, Y.; Bao, Z. "Stabilization of Hexaaminobenzene in a 2D Conductive Metal-Organic Framework for High Power Sodium Storage" J. Am. Chem. Soc. 2018, 140, 10315-10323.

18. Wada, K.; Sakaushi, K.; Sasaki, S.; Nishihara, H. "Multielectron-Transfer-based Rechargeable Energy Storage of Two-Dimensional Coordination Frameworks with NonInnocent Ligands" Angew Chem Int Ed Engl 2018, 57, 8886-8890.

19. Peng, Z.; Yi, X.; Liu, Z.; Shang, J.; Wang, D. "Triphenylamine-Based Metal-Organic Frameworks as Cathode Materials in Lithium-Ion Batteries with Coexistence of Redox Active Sites, High Working Voltage, and High Rate Stability" ACS Appl Mater Interfaces 2016, 8 , 14578-14585.

20. Ferey, G.; Millange, F.; Morcrette, M.; Serre, C.; Doublet, M. L.; Greneche, J. M.; Tarascon, J. M. "Mixed-valence li/fe-based metal-organic frameworks with both reversible redox and sorption properties" Angew. Chem. Int. Ed. 2007, 46, 3259-3263.

21. Fateeva, A.; Horcajada, P.; Devic, T.; Serre, C.; Marrot, J.; Grenèche, J.-M.; Morcrette, M.; Tarascon, J.-M.; Maurin, G.; Férey, G. "Synthesis, Structure, Characterization, and Redox Properties of the Porous MIL-68(Fe) Solid" Eur. J. Inorg. Chem. 2010, 2010, 3789-3794. 22. Aubrey, M. L.; Long, J. R. "A Dual-Ion Battery Cathode via Oxidative Insertion of Anions in a Metal-Organic Framework" J. Am. Chem. Soc. 2015, 137, 13594-13602.

23. Shen, L.; Wang, Z.; Chen, L. "Prussian blues as a cathode material for lithium ion batteries" Chemistry 2014, 20, 12559-12562.

24. Asakura, D.; Okubo, M.; Mizuno, Y.; Kudo, T.; Zhou, H.; Ikedo, K.; Mizokawa, T.; Okazawa, A.; Kojima, N. "Fabrication of a Cyanide-Bridged Coordination Polymer Electrode for Enhanced Electrochemical Ion Storage Ability" J. Phys. Chem. C 2012, 116, 8364-8369. 25. Shin, J.; Kim, M.; Cirera, J.; Chen, S.; Halder, G. J.; Yersak, T. A.; Paesani, F.; Cohen, S. M.; Meng, Y. S. "MIL-101(Fe) as a lithium-ion battery electrode material: a relaxation and intercalation mechanism during lithium insertion" J. Mater. Chem. A 2015, 3, 4738-4744. 26. Zhang, Z.; Yoshikawa, H.; Awaga, K. "Monitoring the solid-state electrochemistry of $\mathrm{Cu}(2,7-\mathrm{AQDC})(\mathrm{AQDC}=$ anthraquinone dicarboxylate $)$ in a lithium battery: coexistence of metal and ligand redox activities in a metal-organic framework" J. Am. Chem. Soc. 2014, 136, 16112-16115.

27. Zhang, Z.; Yoshikawa, H.; Awaga, K. "Discovery of a "Bipolar Charging" Mechanism in the Solid-State Electrochemical Process of a Flexible Metal-Organic Framework" Chem. Mater. 2016, 28, 1298-1303.

28. Du, Z. Q.; Li, Y. P.; Wang, X. X.; Wang, J.; Zhai, Q. G. "Enhanced electrochemical performance of Li-Co-BTC ternary metal-organic frameworks as cathode materials for lithiumion batteries" Dalton Trans 2019, 48, 2013-2018. 